\title{
Biorefinery Review: Wide-Reaching Products Through Kraft Lignin
}

\author{
Iara F. Demuner, ${ }^{\mathrm{a}, *}$ Jorge Luiz Colodette, ${ }^{\mathrm{a}}$ Antonio J. Demuner, ${ }^{\mathrm{b}}$ and Carolina M. Jardim ${ }^{\mathrm{a}}$ \\ This review details the structure of lignin and curates information on the \\ characteristics that this polymer must have for each specific use. Lignin is \\ a by-product of the pulp and paper industry and the second most abundant \\ biopolymer after cellulose. Approximately 50 million tons of lignin are \\ produced worldwide annually, of which $98 \%$ to $99 \%$ is incinerated to \\ produce steam, process energy. Just $1 \%$ to $2 \%$ of the lignin, derived from \\ the sulfite pulp industry, is used in chemical conversion to produce \\ lignosulfonates. Biorefining is a promising approach to promote the wider \\ use of kraft lignin. However, using kraft lignin to produce high value-added \\ products is a great challenge, due to its complex structure, low reactivity, \\ and low solubility, which are factors that limit the lignin's large-scale use in \\ biorefineries. Recent studies show that kraft lignin can be used as \\ lignosulfonates and dispersants, technical carbons, transportation fuels, \\ bioplastics, and adhesives, but some technological hurdles must be \\ overcome and several industrial tests must be developed to make these \\ uses viable.
}

Keywords: Lignin; Biorefinery; Kraft; Chemical modification; Applications

Contact information: a: Department of Forestry Engineering, Federal University of Viçosa, Av. P.H. Rolfs, s/n, Campus, 36570-900 Viçosa, Minas Gerais, Brazil; b: Department of Chemistry, Federal University of Viçosa, Av. P.H. Rolfs, s/n, Campus, 36570-900 Viçosa, Minas Gerais, Brazil; *Corresponding author: iarademuner@gmail.com

\section{INTRODUCTION}

Lignocellulosic biomass (wood and non-wood) is the most abundant renewable material in the world, and its three main components are cellulose, hemicellulose, and lignin. The potential scarcity and increase in the price of fossil fuels, as well as increasing environmental restrictions, makes biomass an important source of renewable energy (Garcia-Maraver et al. 2015). Besides cellulose and hemicellulose, lignin is recognizable as a potential raw material to produce various products.

Lignin is found in large quantities in the cell wall of wood as a highly branched and amorphous biomacromolecule, and it can be diverse in composition, depending on the vegetal source (Sjöström 1993). It is an aromatic polymer with phenolic hydroxyl groups and is the main organic component present in black liquor of the kraft process (Zhu et al. 2014).

As a by-product of the pulp and paper industry, approximately 50 million tons of lignin are produced annually worldwide, of which $98 \%$ to $99 \%$ of the industrial lignin is incinerated to produce steam and energy, while $1 \%$ to $2 \%$, derived from the sulfite pulp industry, is used in chemical conversion to produce lignosulfonates (Mohan et al. 2006; Gellerstedt et al. 2012; Inwood 2014; Norgren and Edlund 2014). Despite the fact that lignin becomes more valuable after its conversion into chemicals (Macfarlane et al. 2009), its application as a source of chemicals remains limited, and most of the kraft lignin in 
black liquor is combusted as a fuel as well as a reductant of sulfate in sulfur recycling.

The kraft and sulfite processes can effectively solubilize and extract lignin from the lignocellulosic biomass, and they are used all over the world. The kraft process is predominant in the pulp and paper sector, giving rise to sizeable amounts of lignin that could potentially yield high value-added products (Ouyang et al. 2009).

The lignocellulose biorefinery concept, based on the chemical separation of the major components (cellulose, hemicelluloses, and lignin) and their further individual processing, is an interesting approach to maximize the added value of the final products (Vila et al. 2016). The pulp industries have specific uses for lignin by-products. For example, the kraft pulp industry uses lignin as a fuel feedstock, while in the sulfite industry the lignin is sold to produce lignosulfonates, after a minor chemical treatment. Nevertheless, it is necessary for biorefinery processes to implement strategies to manage lignin and its by-products, which is essential for establishing the economic viability of the processes (Galkin and Samec 2016; Tian et al. 2017; Huang et al. 2018).

In this context, the biorefining of natural raw materials is a promising approach to promote the wider use of lignin. Such biorefining is based on the integration of biomass conversion, processes, and equipment to produce fuels, energy, and chemicals. In the last few years, the lignocellulosic biorefineries have focused on the valorization of cellulose and hemicellulose, the alleged sugar-based platform, whereas lignin was generally considered to be a low-value residue (Cherubini 2010; FitzPatrick et al. 2010; Doherty et al. 2011). Particularly in the case of the kraft pulp industry, removing part of the lignin from black liquor decreases the heat load to the recovery boiler. Therefore, more black liquor can be combusted in the boiler, and the pulp production can be increased if no other bottlenecks exist. In addition, high value-added products can potentially be obtained from the extracted lignin.

The conversion of lignin into valuable products is a way of unleashing its potential. However, according to Vishtal and Kraslawski (2011), the lignin's complex structure, low reactivity, and solubility are the main factors limiting its large-scale use in biorefineries. Additionally, lignin has a heterogeneous chemical structure and high polydispersity, which can lead to undesirable properties, impacting its applications in new products (Naseem et al. 2016; Roopan 2017; Park et al. 2018).

The use of kraft lignin to produce high-added-value products is a challenge due to the low yield, high costs, the validation of the new products by the performance testing, and the challenges involved in the integration of biorefinery (Wang et al. 2019). However, the combination of a growing market and the potential economic gains related to lignin biorefinery increases the interest in research to evaluate its large spectrum of applications. Kraft lignin can be used as lignosulfonates and dispersants, technical carbons (e.g., carbon fibers), transportation fuels, bioplastics, adhesives, etc.

\section{LIGNIN BIOSYNTHESIS AND STRUCTURE}

Lignin is a natural macromolecule that is biosynthesized from a phenylpropanoid monomer structure, highly amorphous and branched with variable compositions depending on the plant source. In hardwood, lignin makes up $16 \%$ to $24 \%$ of the composition and $25 \%$ to $31 \%$ in softwood (Sjöström 1993; Klemm et al. 2002). In the cell wall, the lignin is chemically bound to carbohydrates by covalent bonds (benzyl esters, benzyl ethers, and phenyl glycosides), forming a structure of excellent resistance and durability (Smook 
2002). The chemical structure of lignin is complex and can be described by the average empirical formula $\left(\mathrm{C}_{9} \mathrm{H}_{10} \mathrm{O}_{2}\left(\mathrm{OCH}_{3}\right)_{n}\right)$, which is based on the phenylpropanoid unit (Kun and Pukánszky 2017).

Like most aromatic constituents of plants, the shikimic acid pathway related to carbohydrates and aromatic amino acids metabolism forms the lignin precursors, which provides the aromatic amino acid phenylalanine, a key step in the lignols biosynthesis (Cesarino et al. 2012; Liu 2012). In the course of the reaction, three hydroxycinnamyl alcohols (monolignols) are formed: p-coumaryl, coniferyl, and sinapyl, originating the lignins 4-hydroxyl phenyl $(\mathrm{H})$, guaiacyl $(\mathrm{G})$, and syringyl (S), respectively (Fig. 1). Their structure differ only regarding the methoxyl groups and its degree of substitution in the aromatic ring.

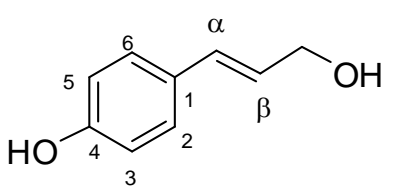

(a)

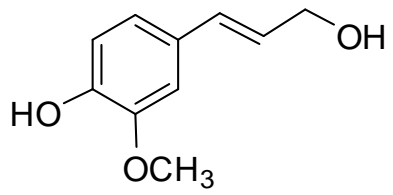

(b)

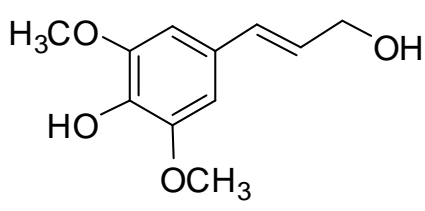

(c)

Fig. 1. Monolignol species: (a) p-coumaryl alcohol (H unit), (b) coniferyl alcohol (G unit), (c) sinapyl alcohol (S unit)

The lignin structure is formed through polymerization by enzymatic oxidation of these three monolignols. The radical sites are initiated by enzymes (e.g., peroxidases or laccases), and the radical-radical combination between lignin monomers leads to the formation of the polymer (Davin et al. 2008; Vanholme et al. 2010). An important variety of inter-unit linkages is known, with the $\beta-\mathrm{O}-4$ ether bonds indicating the most important and frequent type of connection between the lignin units in softwoods and hardwoods, representing approximately $50 \%$ and $60 \%$ of the bonds, respectively (Mašura 1982; Sjöström 1993; Chakar and Ragauskas 2004). In addition, other types of ether bonds $(\alpha-\mathrm{O}-$ $4,4-\mathrm{O}-5)$ are found in lignin with $\mathrm{C}-\mathrm{C}$ covalent bonds ( $\beta-\beta, \beta-5, \beta-1,5-5)$ (Fig. 2 ).

The lignin macromolecule carries multiple functional groups, which are responsible for its reactivity: hydroxyl (either phenolic or aliphatic), methoxyl, carboxyl, carbonyl, benzyl alcohol, hydrolysable ether linkages, and condensed units in C2, C5, and C6 (Sjöström 1993; Brunow et al. 1998; Wang et al. 2017). The chemical reactivity and branching degree of lignin is dependent on the ratio of the three monolignols (Boerjan et al. 2003; Nanayakkara et al. 2009). The different proportions of the monomers in lignin have a high range of variation depending on the type of plant material (e.g., softwood, hardwood, and grasses) and the diversity in inter-unit linkages, resulting in a molecule with a high degree of complexity and heterogeneity (Norgren and Edlund 2014).

In softwoods, the $\mathrm{G}$ unit is dominant, while hardwood lignin normally contains both $\mathrm{S}$ and $\mathrm{G}$ units. In grasses, all 3 types of units are found, but the amount of $\mathrm{H}$ structures is less remarkable than the others (Gellerstedt and Henriksson 2008; Wang et al. 2009). The $\mathrm{H} / \mathrm{G} / \mathrm{S}$ ratio is $0: 5 / 95: 100 / 0$ in softwood, 0:4/25:50/46:75 in hardwood, and 26/38:68/28:60 in grasses (Pinto et al. 2005; Notley and Norgren 2009; Del Río et al. 2012; Djajadi et al. 2018). Del Río et al. (2015) showed that the lignin from sugarcane bagasse is rich in syringyl units $(\mathrm{H} / \mathrm{G} / \mathrm{S}$ molar ratio of $2 / 38 / 60)$, the lignin from sugarcane straw is rich in guaiacyl units (4/68/28), and that both are different in their abundances of the unit linkages. 


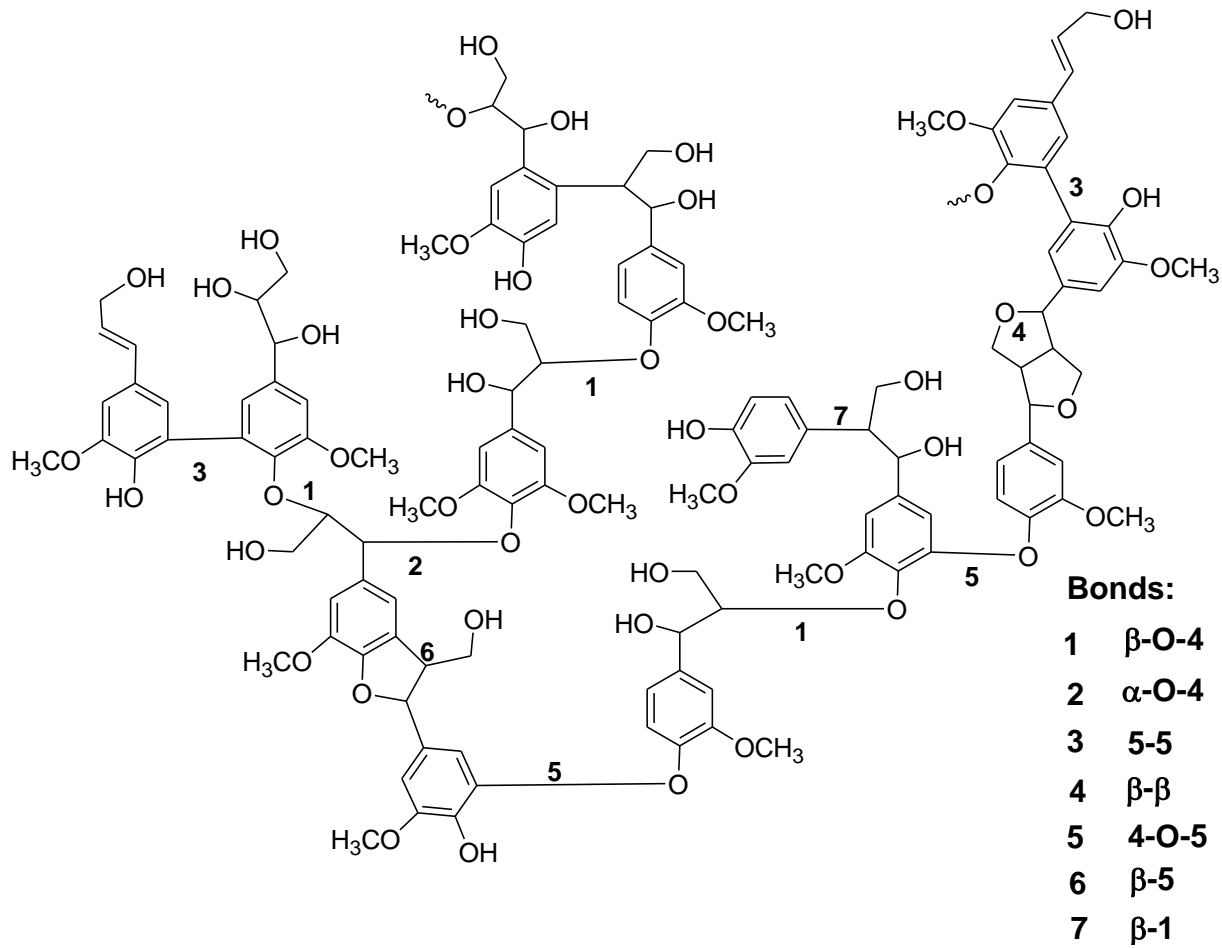

Fig. 2. Main linkages in a softwood lignin. Figure adapted from Windeisen and Wegener (2012).

The $\mathrm{G}$ unit has no methoxyl groups linked on the $\mathrm{C} 5$ of the aromatic ring, leading to a greater possibility of C-C bonds in this position (Sjöström 1993). Therefore, softwood lignin is more condensed than hardwood lignin, and it is less reactive during kraft processes. According to Norgren and Edlund (2014), the lignin isolation from native sources is accomplished by the cleavage of bonds between different lignin monomers, resulting in the chemical modification and formation of fragments of different sizes, with $\mathrm{C}-\mathrm{C}$ bonds proving more difficult to be broken.

\section{LIGNIN INDUSTRIAL EXTRACTION PROCESS}

The pulp industry is the main commercial source of lignin, which is considered a potential by-product of adding value within the concept of biorefinery (Thakur et al. 2014; Jiang et al. 2018). The pulping processes are used to separate the lignocellulosic biomass components. The main processes are kraft, sulfite, soda, and organosolv (not commercial). These lignin extraction processes occur in acid and alkaline media or organic solvents, where lignin is progressively broken into low molecular weight fragments, resulting in changes in its physical-chemical properties (Doherty et al. 2011).

The various processes cause significant degradation and change the structure of the native lignins with a reduction in the amounts of aliphatic $\mathrm{OH}$ groups, $\beta-\mathrm{O}-4$, and $\beta-\beta$ bonds. Additionally, it is possible to observe an increase in the quantities of phenolic hydroxyl groups, carboxylic acids, and carbonyl groups, and in the degree of condensation, due to the formation and/or accumulation of condensed lignin structures (Capanema and Balakshin 2015). Therefore, the structure of the technical lignins is typically dependent on the extraction method and the raw material of origin (softwood, hardwood, or grasses) 
(Berlin and Balakshin 2014; Capanema and Balakshin 2014).

Currently, the sulfite process is responsible for the generation of lignosulfonates, but the kraft process is the most widespread and dominant worldwide. For these reasons, these two processes are detailed below.

\section{Sulfite Process}

Regarding pulp production, the sulfite process is quantitatively less noticeable when compared to kraft process, but it is the most important in terms of marketable lignin, e.g. lignosulfonates with an annual production of approximately 1.8 million tons (Aro and Fatehi 2017).

Traditionally, lignosulfonates are obtained as by-products of sulfite cooking. The wood delignification is carried out by $\mathrm{SO}_{2}$ and $\mathrm{HSO}_{3}{ }^{-}$(acid sulfite), $\mathrm{HSO}_{3}^{-}$(bisulfite), or $\mathrm{HSO}_{3}{ }^{-}$and $\mathrm{SO}_{3}{ }^{2-}$ (neutral sulfite), usually in the presence of a cation, such as sodium, calcium, magnesium, or ammonium, noting that the solubility of each specific sulfite salt is dependent on $\mathrm{pH}$ (Fan and Zhan 2008; Calvo-Flores and Dobado 2010).

The pulping reactions are generally conducted between $140{ }^{\circ} \mathrm{C}$ and $160{ }^{\circ} \mathrm{C}$, and the process $\mathrm{pH}$ is between 1.0 and 2.0 (acid sulfite), 3.0 and 5.0 (bisulfite), and 6.0 and 7.0 (neutral sulfite). The proportions of sulfite, bisulfite, and sulfur dioxide depend on the $\mathrm{pH}$ of the reaction medium, and this affects the path of lignin degradation (Sjöström 1993; Smook 2002).

In the sulfite process, the main reactions that cause lignin solubilization are sulfonation and acid hydrolysis (Elumalai and Pan 2011). The mechanisms involve the loss of a hydroxyl group or the cleavage of the ether bond ( $\alpha-\mathrm{O}-4)$, generating quinone methide intermediates by means of a resonance-stabilized benzylic cation (Fig. 3) (Doherty et al. 2011; Matsushita 2015). Subsequently, large amounts of sulfur become covalently bonded with the lignin as sulfonate groups $\left(-\mathrm{SO}_{3}{ }^{-}\right)$attach to $\alpha$-carbon in amounts ranging from 0.4 to 0.5 sulfonate groups per C9 unit (Goring 1971; Sjöström 1993; Gellerstedt and Henriksson 2008; Lora 2008; Calvo-Flores et al. 2015).

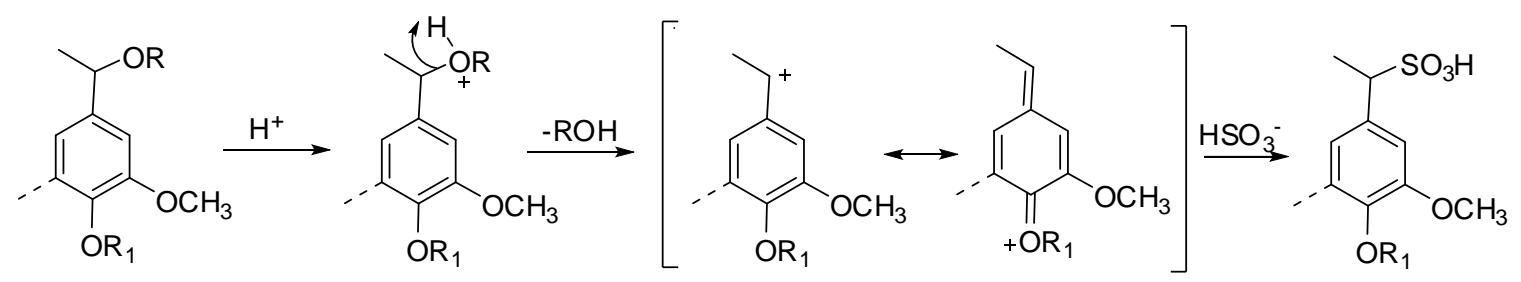

Fig. 3. Sulfonation reaction occurring during acidic sulfite pulping. Figure adapted from Matsushita (2015).

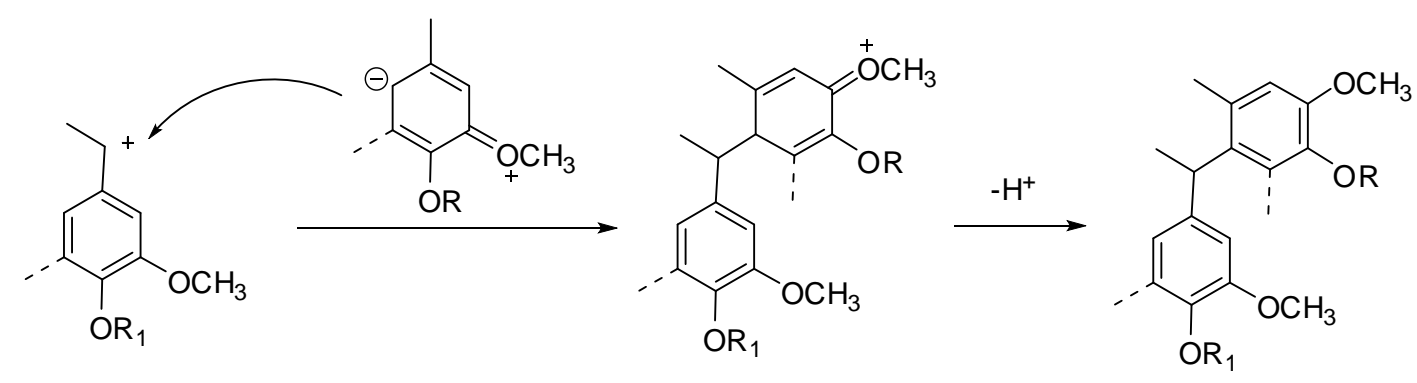

Fig. 4. Condensation reaction occurring during acidic sulfite pulping. Figure adapted from Matsushita (2015). 
Instead of sulfonation, there may be a condensation reaction involving the benzylic carbon of one molecule and another electron-rich carbon atom due to the presence of the benzylic cation (Fig. 4). This condensation tends to block the sulfonation reaction from occurring in the $\alpha$-position (Doherty et al. 2011; Matsushita 2015).

Sulfite pulping does not selectively remove lignin; thus, carbohydrates are highly solubilized (particularly hemicelluloses). The liquor resulting from the sulfite process contains a high content of sugars and chemicals used during the process. The sugar content is an important property of the industrial lignosulfonates because their presence may have negative implications in some applications (Forss et al. 1985). Several purification steps are necessary to obtain lignosulfonates with a higher purity and added value, including fermentation to convert the residual sugars into ethanol, membrane separation, and ultrafiltration (Lora 2008; Aro and Fatehi 2017).

The lignosulfonates generated by the sulfite process have two main ionizing groups, the sulfonates $(\mathrm{pKa} \leq 2)$ and the phenolic hydroxyl groups $(\mathrm{pKa} \sim 10)$, in addition to approximately $5 \%$ by weight of sulfur content (Doherty et al. 2011). The high watersoluble characteristic attributed to lignosulfonates is due to the low $\mathrm{pKa}$ of the sulfonate groups, the variety of functional groups, and other structural characteristics that provide unique colloidal properties to these lignins (Areskogh et al. 2010; Areskogh and Henriksson 2011; Duval and Lawoko 2014).

When compared to kraft lignin ( $\mathrm{MW}=1,000$ to $5,000 \mathrm{~g} / \mathrm{mol}$ ), lignosulfonates generally have higher molecular weights, since only a small part of the more frequent $\beta$ O-4-ether bonds reacts in the pulping process (Aro and Fatehi 2017; Kun and Pukánszky 2017). However, molecular weights may also vary depending on the raw material, with hardwood lignosulfonates exhibiting lower molecular weights ( $\mathrm{MW}=5,700$ to 12,000 $\mathrm{g} / \mathrm{mol}$ ) compared to softwood lignosulfonates ( $\mathrm{MW}=36,000$ to 61,000 g/mol) (Braaten et al. 2003).

The conditions of the pulping process result in different physicochemical properties of lignosulfonates (Aro and Fatehi 2017). For example, the use of sodium cations produces extended lignin chains, which are more suitable for use as dispersants, while calcium cations produce compact lignin chains (Doherty et al. 2011). The lignosulfonates generally have a wide range of uses, such as dispersants, surfactants, animal feed, pesticides formulation, petroleum drilling additives, stabilizers in colloidal suspensions, and as plasticizers in concrete mixtures, which comprise cement, sand, and aggregate (Lora 2008; Fatehi and Ni 2011; Vishtal and Kraslawski 2011; Zhou et al. 2013).

\section{Kraft Process}

Kraft is the world's dominant pulping process. During the kraft process, wood is converted into pulp using a solution of $\mathrm{Na}_{2} \mathrm{~S}$ and $\mathrm{NaOH}$ (white liquor) at a temperature of $155^{\circ} \mathrm{C}$ to $175^{\circ} \mathrm{C}$. In addition, the lignin macromolecule must be degraded and solubilized to a large extent, and the pulping conditions are highly dependent on the chemical structure of the macromolecule (Potthast 2006).

During pulping under alkaline conditions, the degradation or dissolution of phenolic lignin units involves the ionization of phenolic groups and the formation of the quinone methide, an unstable intermediate species (Fig. 5). The bisulfide ions ( $\mathrm{HS}^{-}$) are strong nucleophiles. When present in the liquor, they react with the quinone methide, resulting in the hydrolysis of $\beta$-aryl ether bonds (Gierer 1980). A common characteristic of the kraft process is the nucleophilic reaction of species such as $\mathrm{HO}^{-}, \mathrm{HS}^{-}$, and $\mathrm{S}^{2-}$ (their nucleophilicity increases in the order $\mathrm{HO}^{-}<\mathrm{HS}^{-}<\mathrm{S}^{2-}$ ) with electron-deficient centers in 
the lignin molecule, resulting in the cleavage of lignin interconnections and a higher hydrophilicity of resulting lignin fragments and thus, a better dissolution in the cooking liquor (Potthast 2006). Additionally, the breakage of $\beta$-aryl ether bonds occurs in nonphenolic structures of lignin under specific conditions (e.g., the presence of an $\mathrm{HO}^{-}$group in the $\alpha$-carbon) (Fig. 6).

The hydrolysis of the $\beta$-aryl ether bonds is important because it comprises $40 \%$ to $70 \%$ of the lignin interunit linkages. However, the hydrolysis of the $\alpha$-aryl and $\alpha$-alkyl ether bonds occurs during the kraft pulping process, in addition to the $\beta$-aryl ether bonds (Gierer 1980).

The reactivities of the lignin subunits differ greatly, with the phenolic lignins being noticeably more reactive than the non-phenolic lignin units. Additionally, softwood lignin is less reactive than hardwood lignin, which is due to the G-lignin containing higher amounts of C-C bonds at the C5 position (Sjöström 1993). In general, the kraft lignin contains characteristics that differentiate it from both native lignin and other classes of lignins. Kraft lignin has abundant phenolic hydroxyl groups, which arise due to the extensive breakage of $\beta$-O-4 linkages during the kraft cook (Chakar and Ragauskas 2004).

In addition to the degradation reactions of lignin, condensation reactions occur during kraft pulping, which increase the molecular size of the lignin fragments. Despite having the opposite effect in the delignification process, these two types of reactions are closely related because they proceed through common intermediates (Gierer 1980).

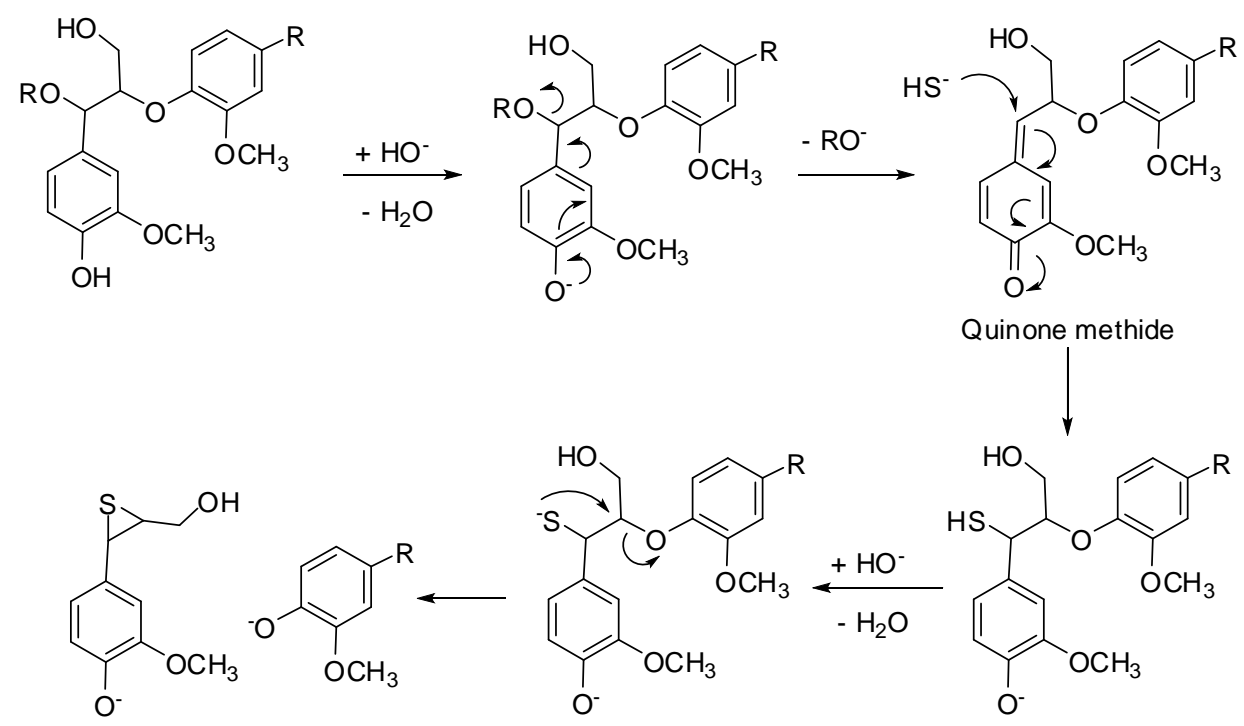

Fig. 5. Cleavage of phenolic $\beta-O-4$ linkages during kraft process. Figure adapted from Gierer (1980)

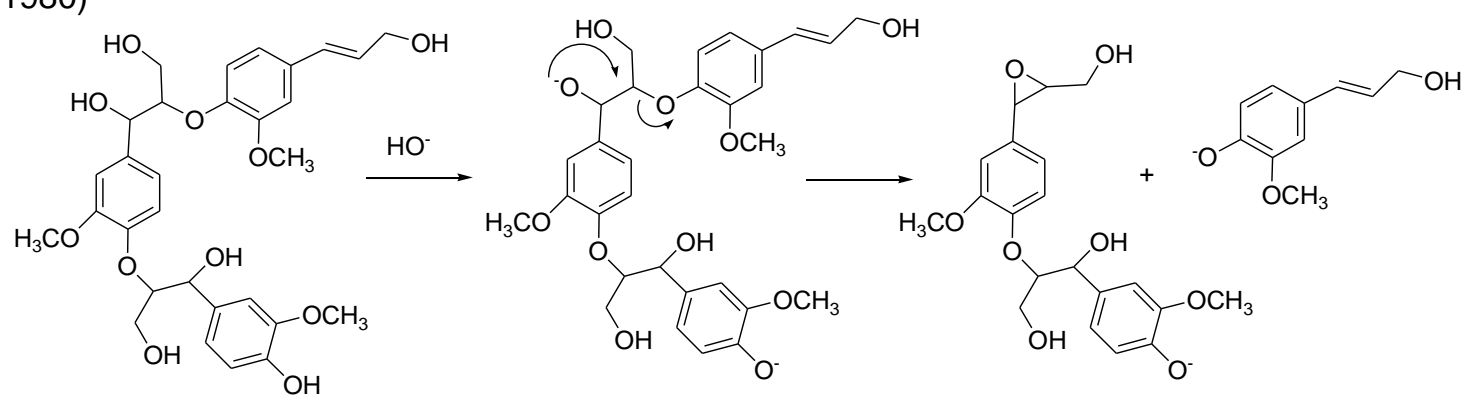

Fig. 6. Cleavage of non-phenolic $\beta-O-4$ linkages during kraft process 
Black liquor is generated by the kraft process as a residual liquor, characterized by the presence of inorganic components as well as organic components that have been removed from the wood. The organic material consists of lignin fragments and hydroxy acids derived from carbohydrates (mainly hemicelluloses) that have been degraded by alkali-catalyzed reactions. According to Krotscheck and Sixta (2006), the black liquor chemical composition depends on the wood species, the composition of and amount of white liquor (solution of $\mathrm{Na}_{2} \mathrm{~S}$ and $\mathrm{NaOH}$ ), the unbleached pulp yield, and the volume of recycled filtrates from the oxygen delignification stage (O-stage). This $\mathrm{O}$-stage uses alkali and oxygen to remove a substantial portion of the residual lignin in the unbleached pulps before a bleaching process. In the pulp mill, the filtrate from the O-stage can be incorporated into the chemical recovery system together with the black liquor, if the recovery boiler has sufficient capacity to handle the extra load (Kvarnlöf and Germgård 2015).

In pulp and paper mills, black liquor is burned in the recovery boiler, which serves as a source of steam for electricity generation and for the drying of paper. Through the kraft recovery cycle, it is possible to recover the inorganic chemical compounds used in the cooking process, providing lower production costs and a considerable reduction of effluents production (Reeve 2002; Tran and Vakkilainen 2008).

The isolation of lignin from black liquor is an important step when converting the pulp mill into a biorefinery to improve the pulp mill throughput and increase the added value of lignin via the generation of usable products (Zhu et al. 2014). Several methods have been evaluated for the separation and purification of lignin (Jönsson et al. 2008; Bhattacharjee et al. 2006; Arkell et al. 2014). The extraction process should be simple and easy, producing a high-yield, isolated lignin, that is free of contaminants (Lin and Dence 1992). Currently, the most commercialized process to recover lignin from black liquor is known as "LignoBoost" (Theliander 2008).

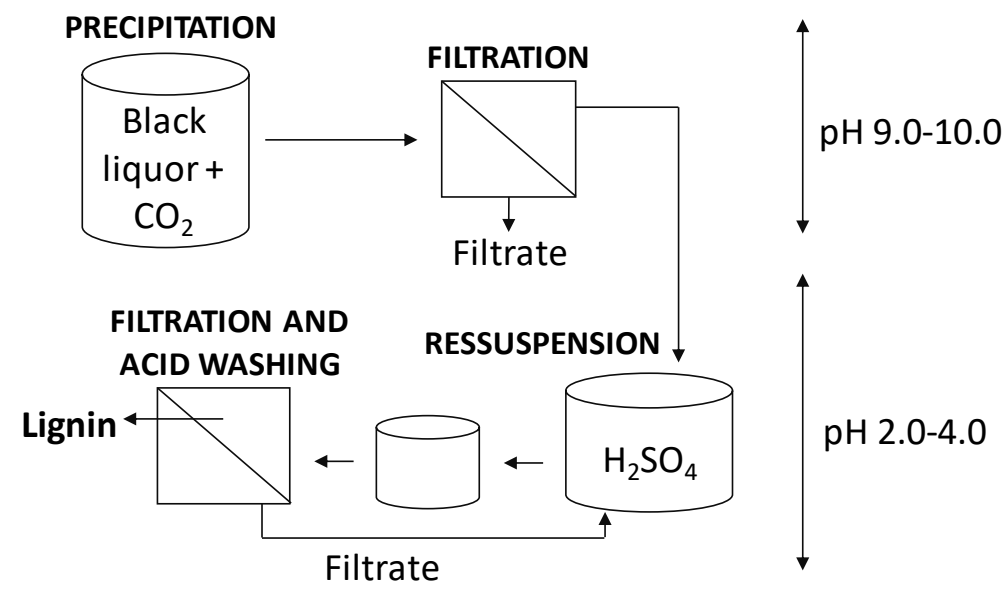

Fig. 7. The LignoBoost process for isolation of kraft lignin

In this process, a black liquor stream is withdrawn from evaporators of the kraft process recovery (dry solid content of $30 \%$ to $45 \%$ ) and is acidified with $\mathrm{CO}_{2}$ to a $\mathrm{pH}$ of 9.0 to 10.0 at $60{ }^{\circ} \mathrm{C}$ to $80{ }^{\circ} \mathrm{C}$. The lignin is precipitated at this $\mathrm{pH}$ in a precipitation tank and filtered. The precipitated lignin is re-dispersed in an acidic filtrate suspension tank with $\mathrm{pH}$ controlled at 2 to 4 (Fig. 7). The resulting lignin is then filtered and washed by acid displacement washing ( $\mathrm{pH}$ of 2 to 3 ) (Kalogiannis et al. 2015). Unlike the lignin separation 
process during a single stage, the change in $\mathrm{pH}$, ionic strength, and lignin solubility occur mainly in the re-dispersion tank and not during the final stage of lignin washing, and this improves the properties of the precipitated lignin (Öhman et al. 2007; Tomani 2010; Fatehi and Chen 2016).

The LignoBoost process has a high lignin yield, high-purity lignin with low ash and carbohydrate contents, low investment costs due to reductions in acid wash volume, and low operating costs due to a reduction in the amount of $\mathrm{H}_{2} \mathrm{SO}_{4}$ required (Tomani 2010). According to Hu et al. (2018), the plant at the Stora Enso Sunila Mill (Kotka, Finland) and the plant at the Domtar Plymouth Mill (Plymouth, NC, USA) manufacture 75,000 tons of kraft lignin per year using the LignoBoost process.

The $\mathrm{pH}$ of black liquor is high ( $\mathrm{pH}$ of 13 to 14), contributing to a high solubility of lignin due to the ionized phenolic groups present in the molecules. The lignin precipitation results from the acidification of black liquor, which results in the protonation of these ionized phenolic groups, reducing the electrostatic repulsive forces between lignin molecules, and making them less hydrophilic (Sundin 2000; Vainio et al. 2004). Protonation takes place to a greater extent at a given $\mathrm{pH}$, in cases where the $\mathrm{pKa}$ value is higher, which is influenced by the temperature, the ionic strength of the solution, and the molecular structure of the lignin (Rudatin et al. 1989; Norgren and Lindström 2000; Ragnar et al. 2000).

The structural difference of softwood and hardwood lignins, according to the type of monolignol units present [softwood $(\mathrm{G})$ or hardwood $(\mathrm{G}$ and $\mathrm{S})$ ], has implication for the reactivity of lignin during kraft pulping, and for the kraft lignin extracted properties. Due to availability of the $\mathrm{C} 5$ position, G-type lignins contain more $\mathrm{C}-\mathrm{C}$ bonds, e.g. $\beta$-C5 and C5-C5, when compared to S-type lignins (Sjöström 1993). According to Zhu and Theliander (2015), precipitated softwood lignin specimens contain lower amounts of methoxyl groups than a mix of hardwood and softwood lignin.

In addition, kraft lignin properties can be altered according to the conditions used during the LignoBoost process. A lower $\mathrm{pH}$ and/or lower temperature and a greater ionic strength in black liquor results in a higher precipitation yield. Under these conditions, the precipitated kraft lignin has a lower average molecular weight and the lignin has a higher number of phenolic groups (Zhu and Theliander 2015).

The main factors that limit the large-scale use of precipitated lignins in biorefineries are the large chemical and molecular variation, their complex structure, low reactivity, and low solubility (Vishtal and Kraslawski 2011; Park et al. 2018). Studies in order to improve solubility and reactivity of lignin may be developed to potentiate the production and generation of high value-added products.

To improve homogeneity and reduce the complexity of lignin, fractionation techniques by an eluotropic series of organic solvents and precipitation by the $\mathrm{pH}$ effect are potential solutions (García et al. 2009; Wang and Chen 2013; Li and McDonald 2014; Santos et al. 2014; Duval et al. 2015). In addition, the use of ceramic membranes having different cut-offs has been widely researched (Wallberg et al. 2003; Toledano et al. 2010). These techniques allow lignin to be produced with more uniform molecular weights and low polydispersity fractions (Francuskiewicz 1994; Li and McDonald 2014; Duval et al. 2015; Jääskeläinen et al. 2017).

Based on the chemical and molecular variations of the precipitated lignins, many possibilities of modifying its structure have been studied to increase the reactivity, to enhance its applications, and to increase the added value of this pulp industry by-product (Hu et al. 2011; Laurichesse and Avérous 2014). 


\section{KRAFT LIGNIN MODIFICATION}

Kraft lignin has limited industrial applications, and it requires modifications to increase its potential for use as a starting material for polymer and chemical synthesis. However, due to the structural complexity and heterogeneity of lignin, such modifications are challenging. Without any modification, the most reactive site in the kraft lignin is the $\alpha$-position of the phenylpropene subunits (Heden and Holmberg 1936). However, this reactive $\alpha$-site can be occupied by ether bonds (e.g., $\alpha-\mathrm{O}-4$ aryl), or be sterically hindered because of $\beta-\mathrm{O}-4$ linkages and other interconnecting bonds, lowering the reactivity of kraft lignin (Inwood 2014).

According to Laurichesse and Avérous (2014), the chemical modification of lignin can be performed through the fragmentation of lignin, the chemical modification of hydroxyl groups, and the creation of new chemically-active sites. To increase the reactivity of the lignin, various methods have been described for modifying its structure, including demethylation, oxidation, hydrolysis, reduction, phenolation, and hydroxymethylation ( $\mathrm{Li}$ and Geng 2005; Effendi et al. 2008; Hu et al. 2011; Inwood 2014; Dai et al. 2016; Zuluaga et al. 2018).

In the lignin structure, the $\mathrm{C} 3$ e $\mathrm{C} 5$ positions of the aromatic ring can be substituted by one or two methoxyl groups $\left(-\mathrm{OCH}_{3}\right)$, and these groups can interfere with the reactivity of the free phenolic hydroxyl group. The demethylation results in lignin with free phenolic groups instead of modifying lignin to form catechol groups (Okamoto et al. 1996; Hu et al. 2011). Sulfur-mediated demethylation and enzymatic oxidative cleavage can remove the methyl groups (Wu and Zhan 2001; Filley et al. 2002). However, in recent studies, a thermal treatment of black liquor prior to the lignin extraction was performed to obtain a significant level of demethylation and demethoxylation in the kraft lignin, a technology known as catechol (CAT) lignin (Wikberg et al. 2017). During the CAT lignin process, a lignin rich in catechol is produced, thus increasing the number of reactive sites. According to Leppävuori et al. (2017), in hardwood lignins, the methoxycatechol units that are formed primarily by demethylation and the demethoxylation will activate the ortho positions of the lignin phenolic unit (C3 and C5).

Lignin oxidation is one way to obtain phenolic derivatives, and the oxidative lignin depolymerization increases the reactivity of lignin through selective bond cleavage of the $\beta-\mathrm{O}-4$, aryl ether, and C-C types (Dai et al. 2016). The application of different oxidants (e.g., nitrobenzene, oxygen gas, hydrogen peroxide, and metal oxides) allows the production of functionalized products that range from aromatic aldehydes (vanillin and syringic) to acids (vanillic and syringic). Nitrobenzene is the aromatic oxidant that promotes the highest yield of derivatives from lignin (Laurichesse and Avérous 2014). To obtain fractions with high value-added compounds, lignins are oxidized under the optimized conditions of temperature, time, and air pressure, with vanillin being considered the most well-known and valuable product from lignin.

The formation of an aldehyde through the oxidative degradation of lignin using alkaline nitrobenzene has been described as a one-electron transfer process (Nandanwar $e t$ al. 2016; Fache et al. 2016; Tarabanko and Tarabanko 2017). This process is demonstrated in Fig 8 with nitrobenzene, but another oxidant can be used. According Fache et al (2016), there are many parameters influencing the process, which increase the complexity of the mechanism.

Hydrolysis is a method to break the ether bonds of lignin, which results in the production of low molecular mass phenolic compounds (Hu et al. 2011). This process can 
be performed with near- and super-critical water using a batch type reactor and an alkaline treatment with $\mathrm{NaOH}$ (Nenkova et al. 2008; Wahyudiono et al. 2008). Despite the fact that hydrolysis increases the lignin reactivity, it decreases the molecular weight, which is undesirable for some applications, e.g., flocculants and dispersants.
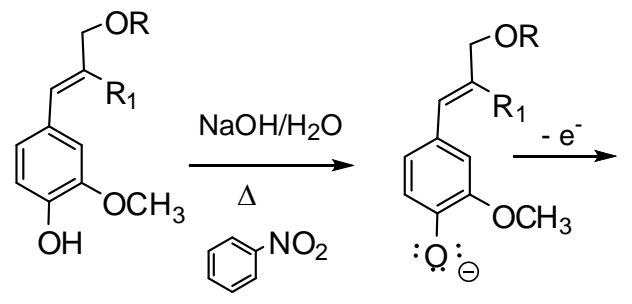<smiles>[R]OC/C([R])=C/c1ccc([O-])c(OC)c1</smiles><smiles>[R]OC([O])=Cc1ccc([O-])c(OC)c1</smiles><smiles>[R]OC([O])/C=C1\C=CC(=O)C(OC)=C1</smiles><smiles>[R]CC([CH])=O</smiles>

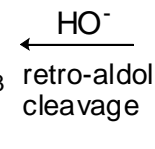<smiles>[R]/C(C=O)=C/c1ccc([O-])c(OC)c1</smiles><smiles>[R]C(=Cc1ccc([O-])c(OC)c1)C([R])([R])CCC</smiles>

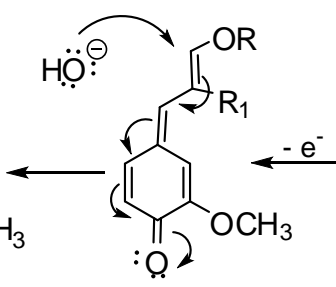<smiles>[R]C(=Cc1ccc(C#[O+])c(OC)c1)C([R])O</smiles>

Fig. 8. Reaction pathway of softwood lignin oxidation giving rise to vanillin. Figure adapted from Fache et al. (2016).

The reduction of lignin takes place during the production of alcoholic groups through the reduction of aldehydes and ketones in the lignin. Some reducing reagents that can be used in this process are lithium aluminum hydride $\left(\mathrm{LiAlH}_{4}\right)$ and sodium borohydride $\left(\mathrm{NaBH}_{4}\right)$. According to $\mathrm{Li}$ and Geng (2005), a demethylated lignin reaction with $\mathrm{NaBH}_{4}$ can form catechol groups, which are regarded as having a higher reactivity than phenol. A strong reagent for hydrogenation (i.e., lithium aluminum hydroxide) can be used to reduce certain groups such as acid and ester, in addition to the aldehydes and ketones into alcohol, although this reagent is selective and does not react with the $\mathrm{C}-\mathrm{C}$ bonds in lignin (Hu et al. 2011).

The phenolation process consists of the treatment of the lignin with phenol in a solution of organic solvents, e.g., methanol or ethanol (Effendi et al. 2008). During the phenolation process in an acidic medium, the phenol condenses in the lignin's aromatic ring at the ortho site relative to the hydroxide group through aromatic substitutions as well as within the chain at the $\alpha$ position (Fig. 9) (Brunow 2005; Inwood 2014; Jiang et al. 2018). Gao et al. (2019) demonstrated that the phenolation of lignin also can occur at the reactive $\gamma$ position by substitution of aliphatic hydroxyl groups. The phenolation reaction is an acidolytic process, where electrophilic substitution reactions of phenolation and condensation occur simultaneously (Huang et al. 2017; Gao et al. 2019).

According to $\mathrm{Hu}$ et al. (2011), the phenolation process, as well as hydroxymethylation, are more effective at increasing the reactivity of lignin when compared with reduction, oxidation, and hydrolysis. The goal of the hydroxymethylation process is to introduce hydroxymethyl groups $\left(-\mathrm{CH}_{2} \mathrm{OH}\right)$ to lignin molecules (Fig. 10), which increases the reactivity of the ortho bonding site in relation to the hydroxide group on the phenyl propene subunit (Yasuda et al. 1999; Zuluaga et al. 2018). 

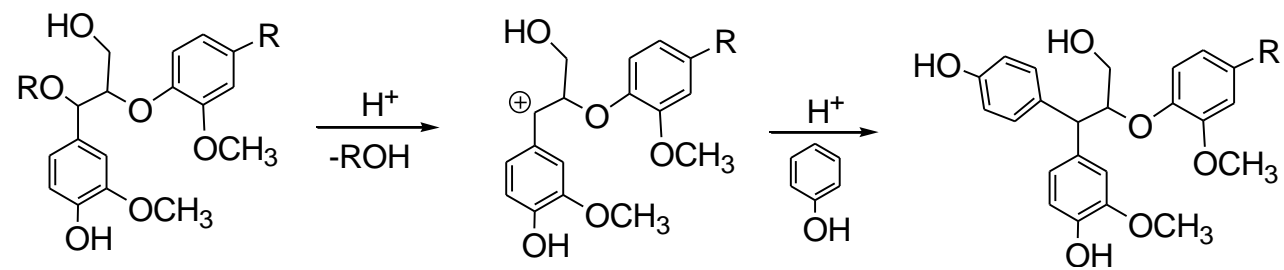

Fig. 9. Reaction pathway of the phenolation of $\beta-O-4$ structure of lignin. Figure adapted from Jiang et al. (2018).

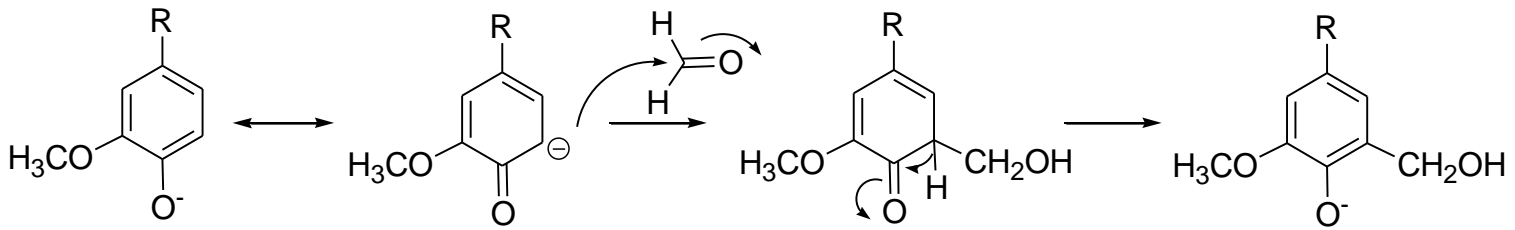

Fig. 10. Reaction pathway of the hydroxymethylation of lignin. Figure adapted from Zuluaga et al. (2018).

\section{KRAFT LIGNIN AS HIGH VALUE-ADDED PRODUCT}

Kraft lignin has a combination of a growing market and a high-level purity in its end-product, which increases its potential for applications in high value-added products. Based on the biorefinery concept, several studies are being carried out to develop wider uses for kraft lignin. In many cases, it is necessary to tune the extraction process or add a process step to reach a specific requirement. When the goal is to improve the reactivity and homogeneity of kraft lignin to compete with petroleum products, depolymerization techniques and chemical modification should be adopted.

\section{Lignin as Lignosulfonates and Dispersants}

The production of lignosulfonates from kraft lignin through sulfonation reactions give rise to a wide range of lignins with different degrees of sulfonation, molecular weights, and functional groups. Although kraft lignin dissolves readily at a high $\mathrm{pH}$, it exhibits poor solubility at a near-neutral $\mathrm{pH}$, and this hinders its use in many systems involving aqueous solutions (Helander et al. 2013). Due to the presence of sulfonic groups, the lignosulfonates are both anionically charged and water-soluble, improving the properties of solubility and charge density of kraft lignin (Aro and Fatehi 2017).

Due to the limited production of lignosulfonates by the sulfite process, an increasing amount of studies focusing on acid sulfonation or sulfomethylation of technical lignins have been performed for the generation of water-soluble sulfonated lignin to satisfy the market demand (He and Fatehi 2015; Konduri and Fatehi 2015). Acid sulfonation consists of the treatment of kraft lignin with sulfuric acid at high temperatures (Inwood 2014). According to Dilling (1991), depending on the degree of sulfonation, the sulfonated lignin may exhibit complete solubility in water at all $\mathrm{pH}$ levels.

In this sulfonation, the $-\mathrm{SO}_{3} \mathrm{H}$ groups are linked to the aliphatic side chain of the lignin molecule, and the reaction occurs at the $\alpha$-carbon of the phenyl propane unit (Fig.11) (Inwood 2014; Sjöström 1993). 


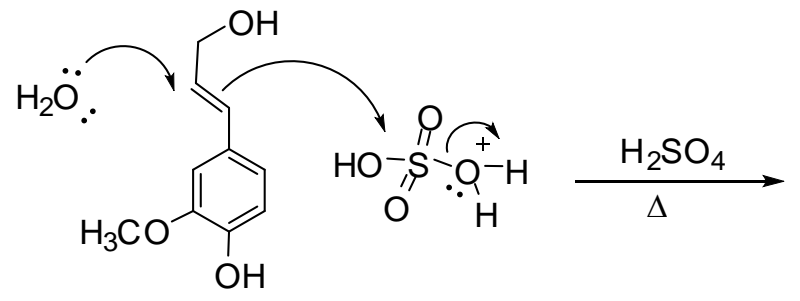<smiles>COc1cc(C(C(O)CO)S(=O)(=O)O)ccc1O</smiles>

Fig. 11. Sulfonation of kraft lignin with sulfuric acid (- $\mathrm{SO}_{3} \mathrm{H}$ groups linked on the aliphatic chain). Figure adapted from Inwood (2014).

According to Gao et al. (2019), the $-\mathrm{SO}_{3} \mathrm{H}$ groups can also be linked to aromatic groups, in $\mathrm{H}$ and $\mathrm{G}$ units of kraft lignin (Fig. 12). A disadvantage of acid sulfonation is that kraft lignin may form condensed structures in the acidic conditions, impairing an extent of lignin sulfonation and its reactivity (Huang et al. 2017).

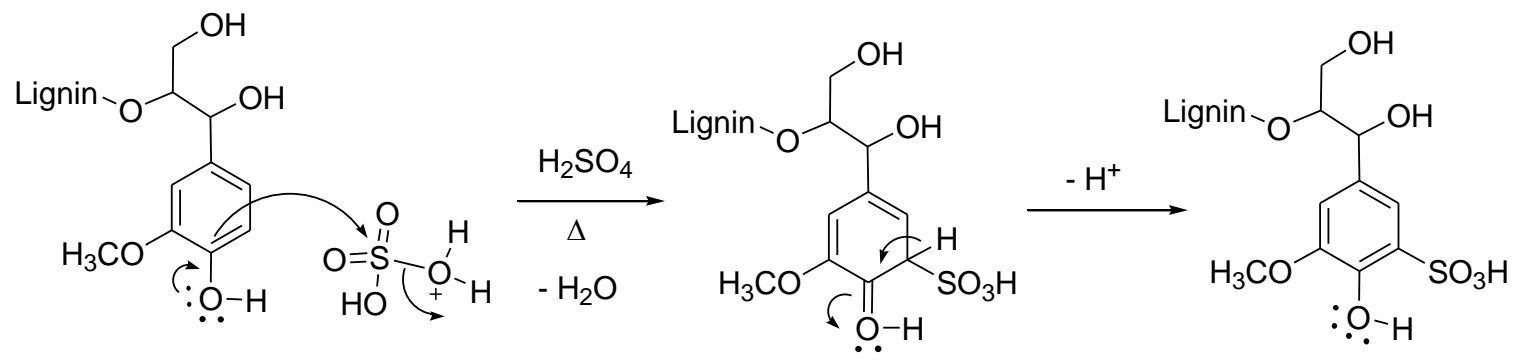

Fig. 12. Sulfonation of kraft lignin with sulfuric acid (- $\mathrm{SO}_{3} \mathrm{H}$ groups linked on the aromatic groups). Figure adapted from Gao et al. (2019).

Sulfomethylation is another alternative to produce sulfonated kraft lignin, and it consists of the treatment of purified lignin with sodium sulfite or sodium bisulfite in the presence of an aldehyde (formaldehyde). Therefore, hydroxymethylation occurs through the addition of formaldehyde, and sulfonation occurs through use of sodium sulfite or sodium bisulfite ( $\mathrm{Yu}$ et al. 2013). The sulfomethylation reaction of the kraft lignin introduces $-\mathrm{CH}_{2} \mathrm{SO}_{3} \mathrm{H}$ groups into the aromatic ring of the lignin structure, according to the mechanism proposed in Fig. 13. Note that lignosulfonate production through sulfomethylation runs through a mechanism completely different from those of the sulfite pulping process and acid sulfonation, in which the sulfonic acid groups are in the aliphatic chain (Berlin and Balakshin 2014). According to Kamoun et al. (2003), in the sulfomethylation reaction, the introduction of sulfonate groups into the aliphatic side chain of the lignin molecule may also occur in the presence of excess sulfite.

However, the sulfomethylation reaction in the aromatic ring is possible only in the guaiacyl lignin present in black liquor, which has the aromatic carbon at the C5 position available for sulfomethylation. Therefore, the sulfomethylation of hardwood kraft lignin is a challenging process due to the high content of low reactivity syringyl lignin present in the kraft liquor.

The kraft lignin can be sulfonated to various degrees, depending on the process conditions. Each water-soluble sulfonated lignin is evaluated through solubility, molar mass distribution, and hydrophilic character (Kamoun et al. 2003). Several applications have been suggested for sulfonated lignins, and the dispersants and additives for concrete (plasticizers) seem to have the most potential. 


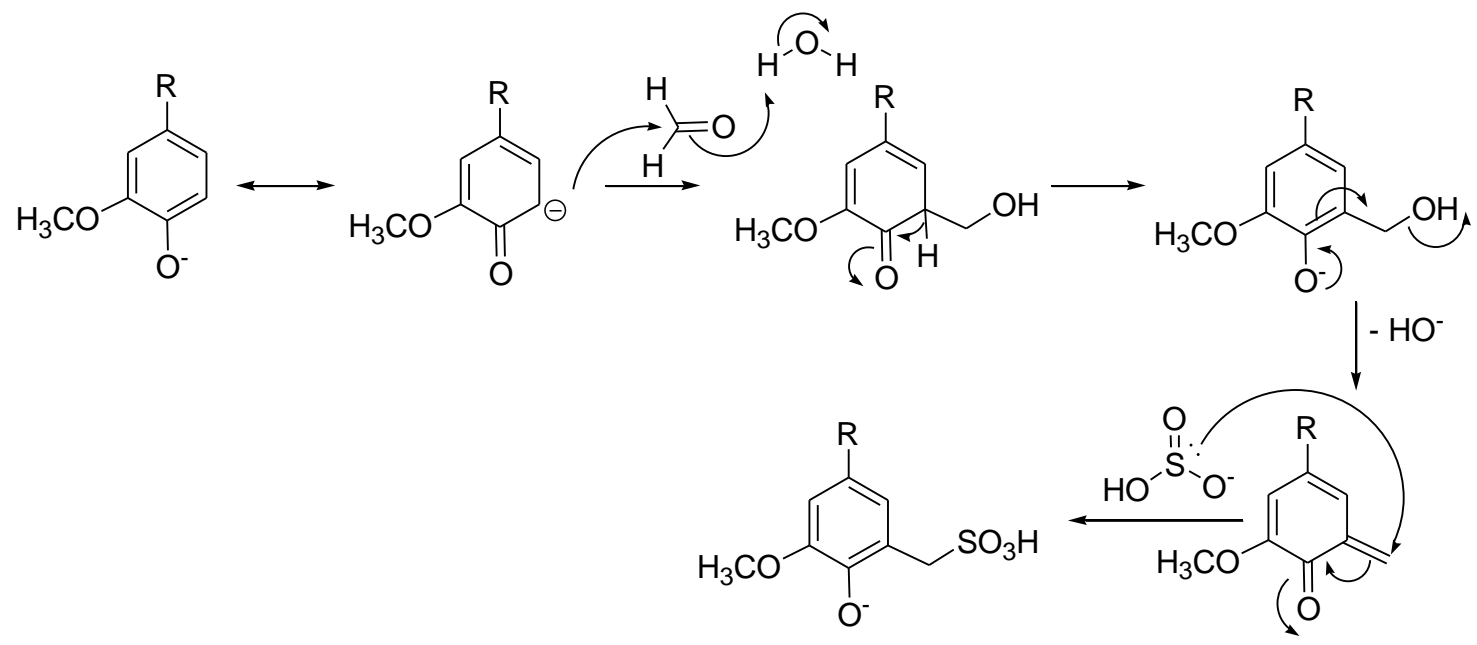

Fig. 13. Proposed mechanism for sulfomethylation of kraft lignin with formaldehyde and sodium sulfite

The preparation of water-soluble sulfonated lignin can be performed with both wood and non-wood lignins. Sulfomethylated lignin from sugarcane bagasse, esparto grass, and a mixture of hardwood were used as dispersant and cement additives (Kamoun et al. 2003; Li and Ge 2011; Konduri and Fatehi 2015). An increase in the degree of sulfonation through the sulfomethylation of kraft lignin will increase the charge density. This provides a lower viscosity to the cement paste in comparison to commercial lignosulfonates and acid sulfonation. The sulfur content of sulfonated lignin is essential for its solubility and dispersion (Aro and Fatehi 2017).

In a study by Inwood (2014) with softwood kraft lignin, the acid sulfonation and sulfomethylation were evaluated, in addition to the application of the products as dispersants and flocculants. In the sulfuric acid treatment, adding charged groups to lignin at an $\alpha$-position occurs on the aliphatic chain. However, lignin condensation (i.e., the polymerization of lignin) can occur on the same site (Yasuda et al. 1999). Due to the balance of these possible reactions, some conditions may negatively influence sulfonation (e.g., temperature). An increase in temperature decreased the charge density because the condensation reaction required less energy than lignin modification (Zoumpoulakis and Simitzis 2001). After optimizing the conditions, a sulfonated lignin with a charge density of $0.75 \mathrm{mEq} / \mathrm{g}$ and a solubility of $8 \%$ was produced.

However, Gao et al. (2019) showed that during acid sulfonation the $-\mathrm{SO}_{3} \mathrm{H}$ groups may also be linked on the aromatic chain, evidencing that this treatment can be effective in sulfonation of kraft lignin.

Sulfomethylation of softwood kraft lignin was performed on previously hydroxymethylated lignin (H-lignin) with formaldehyde (Inwood 2014). The sulfonation with sodium sulfite of this pretreated lignin yielded material having a charge density of 1.2 $\mathrm{mEq} / \mathrm{g}$ and solubility of $100 \%$, evidencing better results when compared with acid sulfonation. The molecular weight (MW) of kraft lignin increased from $25,100 \mathrm{~g} / \mathrm{mol}$ to $37,161 \mathrm{~g} / \mathrm{mol}$, which indicates a slight condensation of lignin. The MW of hydroxymethylated lignin (prior to sulfonation) was 45,420 g/mol, with the decrease being attributed to hydrolysis, which occurs at a high $\mathrm{pH}$ (Mao et al. 2012). The hydrolysis of Hlignin is the dominant reaction, though in addition, condensation in alkaline conditions can occur (Gierer and Petterson 1977). According to Matsushita and Yasuda (2005), the 
increase in the molecular weight helps promote effective dispersion processes due to the application of a larger steric force, thus increasing the efficiency of the products as dispersants.

Sulfomethylated hardwood kraft lignin was successfully prepared by using sodium sulfite and formaldehyde (Konduri and Fatehi 2015). The conditions were optimized, and the unmodified lignin had a negligible charge density and $0.03 \mathrm{mmol} / \mathrm{g}$ of the sulfonate group, while the sulfomethylated lignin presented $-1.6 \mathrm{mEq} / \mathrm{g}$ charge density and 1.48 $\mathrm{mmol} / \mathrm{g}$ of the sulfonate group. The molecular weight increased via sulfomethylation from $22,746 \mathrm{~g} / \mathrm{mol}$ to $53,360 \mathrm{~g} / \mathrm{mol}$, and the solubility analysis confirmed the high solubility (40 $\mathrm{g} / \mathrm{L}$ ) of sulfomethylated hardwood kraft lignin at a neutral $\mathrm{pH}$. In contrast, the unmodified lignin was insoluble at $\mathrm{pH} 7$.

In addition to the benefits of increasing the charge density and sulfonic groups in kraft lignin for the various applications, Huang et al. (2018) observed a high lignosulfonate yield $(94.9 \%)$ through the sulfomethylation of the bamboo kraft lignin with sodium sulfite and formaldehyde, evidencing that the process may be industrially viable.

\section{Lignin as Technical Carbons}

The structure and composition of lignin, which is the largest biomass source with aromatic properties and a carbon content above $60 \%$, make it an ideal precursor to produce advanced carbon materials (Chatterjee and Saito 2015). Carbon fibers, activated carbons, and carbon black are some of the products that can be obtained by thermochemical conversion of kraft lignin (KL) (Rosas et al. 2014).

Carbon fiber is a material with excellent mechanical properties and low density. It is widely used in structures that need to be lightweight but strong, such as sports equipment and in the automotive and aerospace industries (Li et al. 2017a). Carbon fiber production from kraft lignin represents one of its highest value-added products and is discussed in the next topic.

Activated carbon (AC) usually exhibits properties suitable for use as adsorbents, and accordingly it is applied in gas and fluid streams, gas separation, catalyst supports, filtration systems, and electrochemical applications (Bansal and Goyal 2005; Puziy et al. 2018). Activated carbon has thermal and chemical stability in both acidic and alkaline media, easy modification of its chemical surface, well-developed porous structure (with a large internal surface area ranging from $500 \mathrm{~m}^{2} / \mathrm{g}$ to $2000 \mathrm{~m}^{2} / \mathrm{g}$ ), and good adsorption capacities (Suhas et al. 2007; Rosas et al. 2010).

Non-renewable coal-based resources are used to produce approximately $80 \%$ to $85 \%$ of the total production of activated carbon (Ragan and Megonnell 2011). Kraft lignin can partially substitute these non-renewable resources in AC production, due to its high carbon content and high yield of carbon, which is beneficial for the manufacture of AC. In addition, the use of renewable resources reduces carbon emissions during the production process (Puziy et al. 2018). However, the low reactivity of lignin is a challenge for obtaining a quality technical carbon, with high yield and suitable textural properties (Li et al. 2014). Besides that, adjustments in the production process may be necessary.

The manufacture of activated carbon is a two-stage process: (1) carbonization and (2) physical or chemical activation (Ragan and Megonnell 2011). In physical activation, the carbonization process is carried out to form a char (normally nonporous) via pyrolysis, in an inert atmosphere. The char is then activated through contact with an oxidizing gas, resulting in the formation of a well-developed micropore structure (Suhas et al. 2007; Rosas et al. 2014). 
Preparation of activated carbons from eucalyptus kraft lignin through physical activation with $\mathrm{CO}_{2}$ at $800{ }^{\circ} \mathrm{C}$ to $850{ }^{\circ} \mathrm{C}$ has been reported as a viable method (RodríguezMirasol et al. 1993a,b; Bedia et al. 2007; Cotoruelo et al. 2012a, 2012b). The maximum specific surface area is found to range from $700 \mathrm{~m}^{2} / \mathrm{g}$ to $1900 \mathrm{~m}^{2} / \mathrm{g}$. According to Suhas et al. (2007), although they observed high surface areas, the activation times were considerably long, which confirms the low reactivity of lignin due to its cross-linked nature. Fu et al. (2013) used black liquor to prepare AC through physical activation with steam and found the maximum specific surface area to be $310 \mathrm{~m}^{2} / \mathrm{g}$. In this case, the specific surface area was negatively influenced by the higher periods and higher temperatures required for activation.

Impregnation with chemicals such as $\mathrm{H}_{3} \mathrm{PO}_{4}, \mathrm{KOH}, \mathrm{NaOH}, \mathrm{Na}_{2} \mathrm{CO}_{3}, \mathrm{~K}_{2} \mathrm{CO}_{3}$, $\mathrm{H}_{2} \mathrm{SO}_{4}$, and $\mathrm{ZnCl}_{2}$ was followed by heating under a nitrogen flow simultaneously with carbonization. Compared with the physical method, this method produces an activated carbon with higher micropore volumes and wider micropore sizes (Suhas et al. 2007; Supanchaiyamat et al. 2019). Among these activation agents, $\mathrm{H}_{3} \mathrm{PO}_{4}$ and $\mathrm{KOH}$ are preferred to produce $\mathrm{AC}$ from the kraft lignin in the range of $450{ }^{\circ} \mathrm{C}$ to $900{ }^{\circ} \mathrm{C}$ (Hayashi et al. 2000; Fierro et al. 2007; Li and Luo 2013). The textural properties and yield of ACs from kraft lignin are dependent on the lignin pretreatment methods, the activation methods, and the activation conditions (Li et al. 2014).

In a study performed by Gustafsson et al. (2017), AC derived from kraft lignin is produced as a potential sorbent for sediment remediation. Chemical activation via combination was performed with potassium hydroxide $(\mathrm{KOH})$ (lignin/KOH, 1:3 by dry weight) at $700{ }^{\circ} \mathrm{C}$. The sorption tests in water revealed that the softwood kraft lignin presented a similar value to other commercial activated carbons.

Carbon black (CB) is the trade name for a black powder used as a reinforcement filler in rubber products exposed to high wear and tear and plastics products. In addition, $\mathrm{CB}$ is used to make conductive polymer composites (Zhang et al. 2007). Several types of CBs are differentiated by particle size, surface area, and conductivity (Snowdon et al. 2014).

Currently, the raw material that is most used to produce carbon black is heavy fractions of oil. Replacing this compound with a renewable resource, such as kraft lignin, is a great opportunity for the pulp and paper industries. According to Chatterjee and Saito (2015), lignin-based CB is a potential substitute for ordinary CB in ink, paint, reinforcing fillers, and other applications.

A new alternative that meets the specifications for several grades of $\mathrm{CB}$ is the high temperature carbonization process, which converts kraft lignin into $\mathrm{CB}$ of renewable resource and is used by the SunCoal Company. Snowdon et al. (2014) show that the surface area of lignin $654 \mathrm{~m}^{2} / \mathrm{g}$ was obtained with a high carbonization temperature $\left(900{ }^{\circ} \mathrm{C}\right)$. Carbon black has a high surface area, but activated carbon has a higher surface area.

\section{Lignin as Carbon Fibers}

Carbon fiber is defined as a fiber containing at least $92 \mathrm{wt} \%$ carbon and generally has excellent mechanical properties, low weight, high thermal, chemical stabilities in the absence of oxidizing agents, and it conducts both heat and electricity well (Puziy et al. 2018). It has been used in composites, sporting goods, the automotive and aerospace industries, and in wind turbine blades (Mainka et al. 2015; Titirici et al. 2015; Li et al. 2017a).

The principal processing steps for the manufacture of carbon fiber $(\mathrm{CF})$ are shown 
in Fig. 14. Different methods of fiber spinning are used, depending on the raw material's properties, with the melt-spinning method being the most common and preferred method used (Baker and Rials 2013; Meek et al. 2016). Generally, the precursor fibers are first stabilized via oxidation at approximately $200{ }^{\circ} \mathrm{C}$ to $400{ }^{\circ} \mathrm{C}$ in air. After that, the carbonization process is performed at a high temperature (approximately $1,000{ }^{\circ} \mathrm{C}$ ) in an inert atmosphere to remove hydrogen, oxygen, nitrogen, and other non-carbon elements. After carbonization, the fiber can be further graphitized at an even higher temperature (up to approximately $3,000{ }^{\circ} \mathrm{C}$ ) to achieve a higher carbon content (Huang 2009). The surface treatment is performed to improve the interaction between the CFs and the resin matrix, which is when CFs are used as the strength bearing component in composites (Norberg 2012).

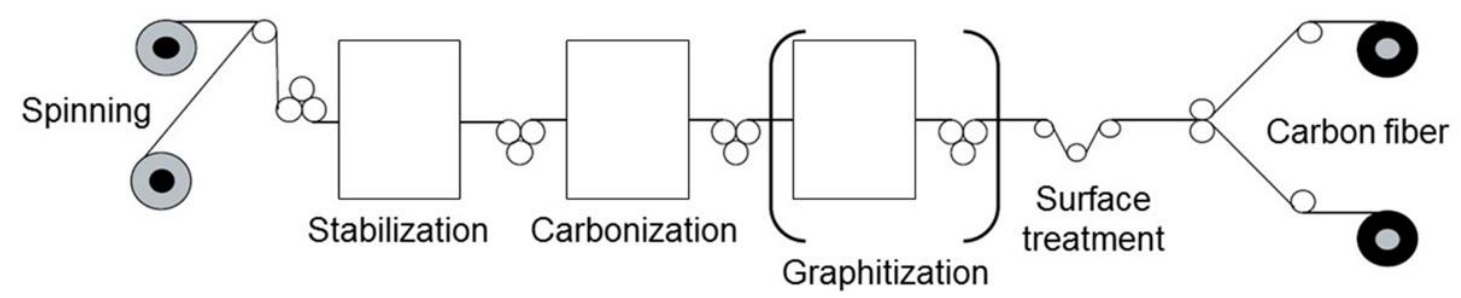

Fig. 14. The principal processing steps for the manufacture of carbon fiber. Figure adapted from Norberg (2012).

Lignin is an attractive precursor to replace polyacrylonitrile (PAN) because of its low cost as a waste from pulp manufacturing facilities. Polyacrylonitrile is a petroleumbased synthetic polymer used to produce approximately $90 \%$ of commercial carbon fibers. Due to the high cost of PAN, production costs accounting for more than half the price tag, there is a cost-limitation for its CF applications (Baker and Rials 2013; Frank et al. 2014; Mainka et al. 2015). Petroleum pitch and regenerated cellulose (rayon) are alternative sources to produce CF. Of these two, lignin is the closest in properties of precursors to petroleum pitch (Norberg 2012).

Lignin as a precursor can promote a broader utilization of carbon fibers. The major advantages of using lignin are its availability, low cost, and high carbon content and high carbon yield during carbonization. In addition, using lignin helps to avoid elimination products such as HCN or nitrous gases released during PAN carbonization (Huang 2009). However, unlike the homogeneous PAN, lignin is a heterogeneous polymer, with different molecular weights, various functional groups, and various chemical linkages. This intrinsic heterogeneity is responsible for the lower mechanical performance of current lignin-based carbon fibers in comparison with petroleum-based carbon fibers (Li et al. 2017a).

The differences in structure between hardwood lignins and softwood lignins can affect the cross-linking ability of lignin and the spinning properties in the CF production process. The difficulties of spinning and thermal mobility of softwood kraft lignin are wellstudied (Kadla et al. 2002; Norberg et al. 2013; Hosseinaei et al. 2016). In contrast, a condensed structure (C-C linkages) and unoccupied C5 sites in lignins with a high $\mathrm{G}$ content (grasses and softwood) result in faster thermostabilization and a reduction of $\mathrm{CF}$ production time (Norberg et al. 2013; Hosseinaei et al. 2016).

The main processing steps to produce carbon fiber include spinning, stabilization, carbonization, and sometimes graphitization. However, to use lignin as a precursor to carbon fiber, the lignin must undergo purification to attain less than $250 \mathrm{ppm}$ ash in the final lignin product and pelletizing the lignin powder into pellets prior to the spinning 
process (Mainka et al. 2015).

Different methods of the spinning process have been investigated, focusing on the manufacture of lignin-based CFs, including both wet and dry spinning, melt-spinning, and electrospinning (Dallmeyer et al. 2010; Thunga et al. 2014; Zhang and Ogale 2014). During the oxidative stabilization, the main reactions in lignin are oxidative, caused by radicals (introduced by homolytic cleavage of the $\beta-\mathrm{O}-4$ ' bond during heat treatment) and rearrangement reactions (Braun et al. 2005). During the carbonization step, the stabilized fiber is converted into a $\mathrm{CF}$, through the elimination of all elements except carbon. The formation of the graphite structure of the lignin-based $\mathrm{CF}$ during this process was established by Mainka et al. (2015).

Alternatives have been developed to potentiate the CFs production from lignin, mainly related to the spinning process enhancement, e.g., chemical modification through the esterification of lignin phenolic groups, hydrogenation, and phenolation, plasticizing lignin through blending with synthetic polymers, such as polyethylene oxide (PEO), polyethylene terephthalate (PET), PAN, and reinforcement with clay or carbon nanotubes (Sudo and Shimizu 1992; Sudo et al. 1993; Uraki et al. 2001; Kadla and Kubo 2004; Kubo and Kadla 2005; Sevastyanova et al. 2010; Thunga et al. 2014; Ding et al. 2016; Liu et al. 2016; Wang et al. 2016; Youe et al. 2016). Additionally, purification and fractionation are used to obtain lignin with high thermal mobility and improved melt-spinning performance.

To improve the homogeneity and reduce the complexity of lignin, fractionation techniques by an eluotropic series of organic solvents and precipitation by the $\mathrm{pH}$ effect are potential options; also, the use of membranes has been thoroughly studied (Brodin et al. 2009; Baker et al. 2012; Nordström et al. 2013; Wang and Chen 2013; Li and McDonald 2014; Duval et al. 2015; Kleinhans and Salmén 2016). These techniques allow lignin to be produced with more uniform molecular weights, thus improving the CF spinning ability and performance (Li and McDonald 2014; Duval et al. 2015).

Li et al. (2017) studied a new approach to fractionate and modify kraft lignin using an oxidation process to treat kraft lignin with laccase and a mediator. The process resulted in lignin fractions with different molecular weights, functional groups, and interunitary linkages. The insoluble fraction of the treated lignin was used with PAN (1:1 ratio) as the starting material for carbon fiber production. The results suggest that the spinnability was improved due to the better miscibility. The elastic modulus of lignin-PAN carbon fiber was similar to those of several commercial carbon fibers (PAN-CF).

\section{Lignin as a Source of Fuels and Chemicals}

Concepts of sustainability and a cleaner environment have encouraged research on replacing fossil fuels with renewable fuels. The development of the lignin-polymer platform in the pulp industry makes it a promising alternative to partially replace oil in the future (Laurichesse and Avérous 2014). Yet, the large-scale production of low-molecularweight chemicals from lignin is still hindered by technological and economic challenges in relation to petrochemicals (Soile and Owoyokun 2014).

Due to the high molecular mass, complex structure, and heterogeneity of kraft lignin, its fragmentation is necessary to obtain renewable biofuels and chemicals (Aysu and Küsük 2014; Ragauskas et al. 2014). The main technologies used are thermochemical processes and biological processes (Gordobil Goñi 2018). Compared to thermochemical fragmentation routes, microbial degradation is expensive and requires an extended reaction period (Berlin and Balakshin 2014).

There are two different thermochemical approaches for the conversion of lignin into 
combustible fuels valorization of lignins: gasification for generating syngas followed by the subsequent conversion of syngas to Fischer-Tropsch synthetic fuels, synthetic alcohols, and hydrogen; and depolymerization to yield aromatics and hydrocarbons with molecular weights ranging from about 100 to $300 \mathrm{Da}$ (Azadi et al. 2013).

The gasification process converts kraft lignin into a gas called syngas consisting of $\mathrm{CO}_{2}, \mathrm{CO}, \mathrm{CH}_{4}, \mathrm{H}_{2}$, and $\mathrm{H}_{2} \mathrm{~S}$ within a temperature range of $700{ }^{\circ} \mathrm{C}$ to $1000{ }^{\circ} \mathrm{C}$ (Gordobil Goñi 2018). Syngas is used to generate electricity, pure hydrogen, and synthetic liquid fuels and chemicals (Azadi et al. 2013). According to Huber et al. (2006), the Fischer-Tropsch (FT) method is used to convert syngas components $\left(\mathrm{CO}\right.$ and $\left.\mathrm{H}_{2}\right)$ to liquid transportation fuels by a chemical catalyst such as a metal (e.g., Fe) in the reactor (Fig. 15). Conventional diesel, kerosene, and gasoline can be produced from hydrocarbons of different lengths formed during the FT process (Verma et al. 2016).

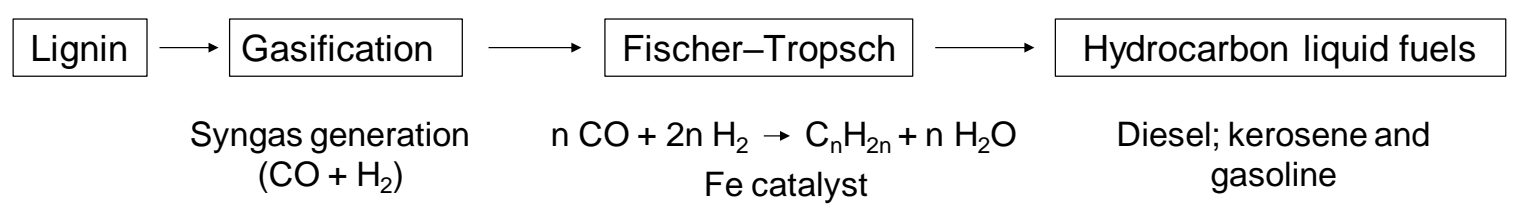

Fig. 15. Process to produce liquid fuels from lignin

A major challenge of using syngas is sulfur contamination by hydrogen sulfide $\left(\mathrm{H}_{2} \mathrm{~S}\right)$. These gases must be removed by means of intensive purification steps, adding to the cost of production. In addition, FT synthesis requires expensive catalysts, a fixed $\mathrm{H}_{2} / \mathrm{CO}$ ratio, and extreme temperature and pressure conditions in the reactor (Verma et al. 2016).

The depolymerization process is used to convert the complex lignin compound into small molecules with low molecular weight, such as vanillin, unsubstituted and hydroxylated aromatics, aldehydes, aliphatic acids, etc. (Kim et al. 2015). Pyrolysis, catalytic hydrogenolysis, alkaline hydrolysis, solvent depolymerization, supercritical water, and alkaline oxidation are well-known depolymerization techniques (Pandey and Kim 2011; Azadi et al. 2013). According to Ponnusamy et al. (2019), the viability of lignin depolymerization depends on the depolymerization technique and the chemical composition of the technical lignin.

Among the depolymerization techniques can be mentioned the degradation by fungi and bacteria (microbial degradation), thermochemical depolymerization (base-catalyzed, acid catalyzed, metal catalyzed and, conventional pyrolysis of lignin) and electrochemical depolymerization of kraft lignin. All lignin degradation approaches are either expensive, consume more energy, or even produce toxic by-products, except for biological degradation. Then, it is a challenging process the controlled degradation of lignin into desired chemical compounds (Agarwal et al. 2018).

None of these processes will provide a high yield of monomers or high selectivity of the reaction products. However, lignin can be depolymerized into its aromatic monomer constituents (Azadi et al. 2013). These products can be blended into transportation fuels, given that aromatic hydrocarbons constitute approximately 35\% to 50\% of gasoline and $26 \%$ to $30 \%$ of diesel (Merker et al. 2011).

Regarding the use of kraft lignin for renewable chemicals, aromatic aldehydes such as vanillin (4-hydroxy-3-methoxybenzaldehyde) and syringaldehyde (4-hydroxy-3,5dimethoxybenzaldehyde) are used as additives in foods, beverages, and pharmaceuticals (Pacek et al. 2013; Tarabanko and Tarabanko 2017). Currently, most of the vanillin is 
produced from petrochemical sources, but producing vanillin from kraft lignin is more environment-friendly and potentially economical than from guaiacol (Pinto et al. 2012).

Producing vanillin from kraft lignin faces challenges, such as having a low yield. This has been attributed to the difficulty purifying the vanillin products, mainly in hardwood, which contains less G-type lignin than softwood. In addition, lignin depolymerization has a high demand for energy, as well as high requirements for acids and organic solvents during the extraction process (Fache et al. 2016; Wongtanyawat et al. 2018).

The yield of aldehydes depends on the source of lignin, the condition of its isolation, and the condition of lignin oxidation (Tarabanko and Tarabanko 2017). In a study performed by Wang et al. (2018), three technical lignin samples were oxidized by alkaline nitrobenzene to evaluate their feedstock potential for vanillin production. They showed that the $\beta$-O-4 linkages in lignin affected its aldehyde yield. Kraft lignin showed a lower vanillin yield when compared to alkali lignin and sodium lignosulfonate.

Yoshikawa et al. (2013) performed an optimization of a two-step process to produce phenols from kraft lignin. First, lignin was depolymerized into liquid products with lower molecular weights using a $\mathrm{H}_{2} \mathrm{O} / \mathrm{BuOH}$ solution. Next, lignin catalytic cracking was carried out in the lignin-derived slurry liquid over $\mathrm{ZrO}_{2}-\mathrm{Al}_{2} \mathrm{O}_{3}-\mathrm{FeOX}$, and there was an increase in the total recovered fraction of phenols.

\section{Lignin as Bioplastics and Coatings}

A continuous increase in oil prices and an environmental concern with the use of common petroleum-based plastics has resulted in a growing interest in eco-friendly materials. Kraft lignin can be used as an additive or raw material to produce new plastics (Kun and Pukánszky 2017). Currently, the most common commercial thermoplastics used by the polymer industry for food packaging and bottles are polypropylene (PP), polyethylene (PE), polystyrene (PS), and polyethylene terephtalate (PET) (Gordobil Goñi 2018).

Lignin can be used in polymer-lignin blends (e.g., plastics blends), as an ultraviolet and thermal stabilizer, and to improve the mechanical properties and processability (Stewart 2008; Doherty et al. 2011; Laurichesse and Avérous 2014). In addition, the phenolic structure inherent in lignin enables it to function as a free radical scavenging antioxidant in plastics, similar to the commercial phenol-based antioxidants (Egüés et al. 2012; Lu et al. 2012).

The depolymerization of kraft lignin is required for its use in polymers (e.g. polyethylene and polypropylene) because the unmodified lignin exhibits a large molecular mass as well as low reactivity and low compatibility with other polymers. This process has the potential of decreasing the molecular weight, reducing the hydrophilicity, increasing the phenolic content, and decreasing the aliphatic hydroxyl content of lignin (Kabir 2017). These characteristics increase the antioxidant activity of the lignin (Pan et al. 2006; Ugartondo et al. 2008).

In a study performed by Kabir (2017), the depolymerized kraft lignin presented more thermo-oxidative stability than unmodified species and used a 5\% addition of kraft lignin as an antioxidant for polyethylene (PE) and polypropylene (PP). Additionally, the depolymerization improved the compatibility of the lignins with the non-polar polymer matrix by decreasing the aliphatic hydroxyl content and improving the hydrophobicity.

Chemical modification may be performed to achieve a uniform distribution of lignin with non-polar polymers in order to not affect the polymer's mechanical properties. 
Esterification is often used as a chemical pre-treatment when manufacturing lignin-based polymers to reduce the polarity (Maldhure et al. 2011; Maldhure et al. 2012; Gao 2017). However, alkylation can be performed to decrease the number of hydroxyl groups responsible for lignin's polar character (Chen et al. 2011; Maldhure et al. 2012).

Acetylated softwood kraft lignin (ASKL) was used as filler in synthetic polymers (PE, PP, PS, and PET), and the acetylated lignin was more thermally-stable than the unmodified lignin (Jeong et al. 2012). The miscibility between ASKL and the synthetic polymers was favorable, reflecting positively on the tensile properties of ASKL and synthetic polymers. In another study, the properties of lignin-polyethylene blends were evaluated according to the raw material used (Dehne et al. 2016). Kraft lignin of hardwood and softwood were esterified and the results did not show any clear influence of the source of the raw material on mechanical properties. Despite this, the esterification of lignin turned out to be beneficial for the blend properties.

The use of kraft lignin is also being studied to improve biodegradable polymers. A known biodegradable thermoplastic is polylactic acid (PLA), which can be manufactured from renewable resources, and processed in conventional equipments by condensation of lactic acid or ring opening polymerization of lactide. It has desirable properties such as high strength and high stiffness, but it is too expensive to be widely used and possesses low thermal resistance and flexibility, which could be overcome by using lignin as an additive (Spiridon et al. 2015; Vila et al. 2016; Gao 2017). In a study performed by Spiridon et al. (2015), new bioplastics were obtained by melt compounding softwood kraft lignin (7\%) with PLA. Adding lignin improved the thermal stability and the mechanical properties (elastic modulus and impact strength) of PLA. Gordobil Goñi et al. (2015) observed an increase in the thermal stability of PLA when kraft lignin is added; however, they recommend adding no more than 5\% of lignin. Performing lignin chemical modification (acetylation) resulted in improving the compatibility with the PLA matrix, which was reflected in the observed mechanical properties.

For use in coating, kraft lignin needs to be depolymerized and/or chemically modified (Mulder et al. 2011; Gao 2017). An industrial softwood kraft lignin was used for coating in combination with PLA to improve the slow release of urea. The lignin was esterified for hydrophobicity development, which improved the water barrier property of the coating, thus increasing the efficiency of the nitrogen fertilizer ( $\mathrm{Li}$ et al. 2017b). Additionally, the esterified kraft lignin is a potential material for sustainable coating applied to replace the conventional petroleum-based materials. According to Hult et al. (2013), kraft lignin can be used as a barrier in fiber-based packaging materials.

Softwood kraft lignin was used as polyurethane coatings (Griffini et al. 2015). Solvent extraction with MeTHF was used to improve the homogeneity of kraft lignin, and the MeTHF-soluble lignin fraction was used to polyurethane synthesis. The results showed that a viable strategy for the development of advanced lignin-based PU thermosetting systems can be obtained with the direct reaction of fractionated lignin with polyisocyanates. Besides that, the authors highlighted the potential of lignin-based thermoset PUs as sustainable bioderived materials for application in the field of high performance coatings and adhesives. Klein et al. (2018) considers the kraft lignin as a renewable resource for the production of bio-based polyurethane coatings for application in areas such as construction.

Hajirahimkhan et al. (2019) performed a reaction with kraft lignin and methacrylic anhydride in tetrahydrofuran solvent. They demonstrated that the obtained methacrylated lignin (ML) is curable in a UV-cured coating system with positive effects on the 
hydrophobicity, crosslinking percentage, and thermal stability of the coating system in which it was incorporated. Thus, the ML as an environmentally friendly UV-curable material for UV-cured coatings.

In addition to the necessary changes in kraft lignin, another challenge is the odor found in lignin-based composites, such as bioplastics, coating, binders, or adhesives because the characteristic odor can persist even when using pure lignin (Kalliola et al. 2012). The compounds that contribute to the scent are guaiacol and ethyl-guaiacol and not the sulfurous compounds (i.e., dimethyl disulfide, dimethyl trisulfide, and dimethyl tetrasulfide). Softwood kraft lignin is primarily composed of G-type lignin, a potential source for guaiacol production, which is an important aromatic monomer in depolymerized lignin (Barton et al. 2018; Feng et al. 2019).

Therefore, the guaiacol must be removed from the lignin to be applied in situations that require a totally odorless material. Two pending patents have been developed to accomplish the removal of guaiacol: (1) the guaiacol removal treatment takes place during the lignin precipitation and washing process, removing approximately $60 \%$ of the compound, and (2) the washed lignin is treated, i.e., after the lignin extraction and washing treatment; the latter approach is considered efficient due to the removal of approximately 97\% of the guaiacol (Valmet 2017).

\section{Lignin as Adhesives and Binders}

The adhesives based on phenol-formaldehyde (PF) are used as a binder to produce wood-based composites such as plywood, laminated veneer lumber, glue-laminated timber, fiberboard, and particleboard (Malutan et al. 2007; Bertaud et al. 2012). Reacting phenol with formaldehyde is conducted in an alkaline medium, and the process conditions (e.g., phenol-formaldehyde ratio, $\mathrm{pH}$, time, and temperature) determine certain physical and chemical properties of the adhesives, such as viscosity and the overall mechanical properties of the final glued product (Xu et al. 2012; Ghorbani et al. 2016).

Due to the possible future scarcity of fossil resources and global environmental concerns, the consumption of synthetic adhesives needs to be reduced (Solt et al. 2018a). Due to its availability and low cost, kraft lignin is a potential source of bio-phenol to substitute as the petroleum-based phenol when manufacturing phenolic resins (Yang et al. 2019).

Currently, the use of kraft lignin in PF resins is limited in its commercial application because lignin has a lower reactivity with formaldehyde compared with phenol, and the lignin-phenol-formaldehyde requires higher curing temperatures (Siddiqui 2013). Chemical modifications in the complex structure of lignin to improve its reactivity for use as adhesives have been studied with moderate success, e.g., phenolation and demethoxylation (Hu et al. 2011; Laurichesse and Avérous 2014; Ghorbani et al. 2018).

In addition, the technique of solvent fractionation to improve the lignin homogeneity was studied and resulted in resins of lower strength values compared with commercial PF resins (Solt et al. 2018b). Fractions with lower molecular mass are more reactive due to increased content of phenolic hydroxyl groups from the depolymerization of kraft lignin and reduced steric hindrance (Mahmood et al. 2013; Siddiqui 2013). However, fragments with a high molar mass have a better chance of contributing to polymerization (Tejado et al. 2007).

Despite the large variety of lignin's molar mass, the functional groups of different lignin raw materials can impair its applicability as a binder in adhesives. Unlike phenol, in which electrophilic aromatic substitution can take place at the para and the two ortho 
positions, many reactive sites of lignin's aromatic ring are methoxylated or occupied by other groups, which impedes the reactions with formaldehyde (Hu et al. 2011; Ghorbani et al. 2016).

Another chemical property of lignin involved in polymerization reactions is the presence of hydroxyl groups (phenolic and aliphatic). According to Yang et al. (2019), because of activation of the aromatic ring in the ortho position, phenolic hydroxyl groups increase the reactivity of lignin with formaldehyde.

Hardwood lignin is less reactive than the softwood type because S-type lignin contains both ortho positions occupied by methoxyl groups. Ghorbani et al. (2016) substituted $20 \%$ of phenol with pine kraft lignin and the phenol-formaldehyde adhesive performed similarly. The G-type kraft lignin of pine is superior to the hardwood lignin with respect to phenol replacement due to its high molecular weight and high amount of activated free ring positions (Ghorbani et al. 2016).

Presently, a promising method to increase lignin's applicability is the conversion of the polymer into smaller fragments through depolymerization. These fragments exhibit increased chemical reactivity because they are structurally similar to phenol (Cheng et al. 2013; Wang et al. 2013; Rößiger et al. 2018). Therefore, the depolymerized lignin is an interesting alternative to phenol substitution. In this case, higher substitution levels are achieved due to increased reactivity of the low-molecular-mass lignin fragments (Siddiqui et al. 2017; Solt et al. 2018a).

Pine kraft lignin was cracked using a base-catalyzed depolymerization process (250 bar, $320^{\circ} \mathrm{C}$, and $10 \mathrm{~min}$ ) to obtain oligomeric lignin units (Solt et al. 2018a). The results demonstrated that the lignin oligomers can successfully replace phenol in PF resins at high substitution levels (up to 70\%). No penalties were observed on the final dry or wet tensile shear strength, and the time of bond strength development was fully comparable with that of the $\mathrm{PF}$ reference at the $120^{\circ} \mathrm{C}$ hot pressing temperature. However, the high viscosity of the lignin-phenol-formaldehyde (LPF) resin still poses a challenge for industrial applications.

In addition to the substitution of phenol to manufacture adhesives, lignin has been studied as binder material for eco-friendly Li-ion batteries. To assemble electrodes in Liion batteries, three components are employed: an active material, a conductive material, and a binder (the conventionally-used binding material is polyvinylidene fluoride (PVDF)) (Chen et al. 2003). Currently, it is essential to develop alternative binders that are nonfluorinated, less costly, and more environment-friendly (Lu et al. 2016; Nirmale et al. 2017).

The main study using lignin as a binding material for Li-ion battery electrodes was performed by Lu et al. (2016). A lignin pretreatment needs to be performed to remove the soluble, low-molecular-weight fractions of lignin. Electrodes based on pretreated lignin exhibit a relatively high specific capacity and a good stability, evidencing that lignin is a promising binding material for electrodes.

\section{SUMMARY AND OUTLOOK}

A steady increase in the interest of producing high value-added products from kraft lignin is evident based on the combination of a growing market, increasing environmental restrictions with the use of non-renewable fuels, and the economic return of the lignin biorefinery. 
The potentials and opportunities of providing the pulp and paper industries with the capacity to act as a biorefinery based on lignin are being exhaustively studied. Kraft lignin can be used as lignosulfonates and dispersants, technical carbons (e.g., carbon fibers), transportation fuels, bioplastics, and adhesives. For some end markets, however, specific lignin requirements and/or specifications are needed to reach the conditions set for the final product (e.g., a water-soluble lignin is a prerequisite for producing lignosulfonates from kraft lignin).

In order to exploit different applications, challenges remain, especially in terms of the structure complexity, heterogeneous nature, and low reactivity of lignin. The lignin from different raw materials (hardwood, softwood, and grasses) is different, which may have a direct impact on the final product. In some cases, changes in the extraction process to reach a specific requirement may additionally be necessary to enable current pulp industries to act as lignin biorefineries and expand their commercial potential.

\section{REFERENCES CITED}

Agarwal, A., Rana, M., and Park, J. H. (2018). “Advancement in technologies for the depolymerization of lignin," Fuel Processing Technology 181, 115-132. DOI: 10.1016/j.fuproc.2018.09.017

Areskogh, D., and Henriksson, G. (2011). "Immobilisation of laccase for polymerisation of commercial lignosulphonates," Process Biochemistry 46(5), 1071-1075. DOI: 10.1016/j.procbio.2011.01.024

Areskogh, D., Li, J., Gellerstedt, G., and Henriksson, G. (2010). "Investigation of the molecular weight increase of commercial lignosulfonates by laccase catalysis," Biomacromolecules 11(4), 904-910. DOI: 10.1021/bm901258v

Arkell, A., Olsson, J., and Wallberg, O. (2014). "Process performance in lignin separation from softwood black liquor by membrane filtration," Chemical Engineering Research and Design 92(9), 1792-1800. DOI:

10.1016/j.cherd.2013.12.018

Aro, T., and Fatehi, P. (2017). "Production and application of lignosulfonates and sulfonated lignin," ChemSusChem 10(9), 1861-1877. DOI: 10.1002/cssc.201700082

Aysu, T., and Küçük, M. M. (2014). "Biomass pyrolysis in a fixed-bed reactor: Effects of pyrolysis parameters on product yields and characterization of products," Energy 64, 1002-1025. DOI: 10.1016/j.energy.2013.11.053

Azadi, P., Inderwildi, O. R., Farnood, R., and King, D. A. (2013). "Liquid fuels, hydrogen and chemicals from lignin: A critical review," Renewable and Sustainable Energy Reviews 21, 506-523. DOI: 10.1016/j.rser.2012.12.022

Baker, D. A., and Rials, T. G. (2013). "Recent advances in low-cost carbon fiber manufacture from lignin," Journal of Applied Polymer Science 130(2), 713-728. DOI: 10.1002/app.39273

Baker, D. A., Gallego, N. C., and Baker, F. S. (2012). "On the characterization and spinning of an organic-purified lignin toward the manufacture of low-cost carbon fiber," Journal of Applied Polymer Science 124(1), 227-234. DOI: 10.1002/app33596

Bansal, R. C., and Goyal, M. (2005). Activated Carbon Adsorption, CRC press, New York, NY.

Barton, N., Horbal, L., Starck, S., Kohlstedt, M., Luzhetskyy, A., and Wittmann, C. (2018). "Enabling the valorization of guaiacol-based lignin: Integrated chemical and 
biochemical production of cis,cis-muconic acid using metabolically engineered Amycolatopsis sp ATCC 39116," Metabolic engineering 45, 200-210. DOI: 10.1016/j.ymben.2017.12.001

Bedia, J., Rodríguez-Mirasol, J., and Cordero, T. (2007). “Water vapour adsorption on lignin-based activated carbons," Journal of Chemical Technology \& Biotechnology 82(6), 548-557. DOI: 10.1002/jctb.1698

Berlin, A., and Balakshin M. (2014). "Industrial lignins: Analysis, properties, and applications," in: Bioenergy Research: Advances and Application, V. G. Gupta, M. Tuohy, C. P. Kubicek, J. Saddler, and F. Xu (eds.), Elsevier, Oxford, UK, pp. 315336.

Bertaud, F., Tapin-Lingua, S., Pizzi, A., Navarrete, P., and Petit-Conil, M. (2012). "Development of green adhesives for fibreboard manufacturing, using tannins and lignin from pulp mill residues," Cellulose Chemistry and Technology 46(7-8), 449455.

Bhattacharjee, C., Sarkar, P., Datta, S., Gupta, B. B., and Bhattacharya, P. K. (2006). "Parameter estimation and performance study during ultrafiltration of kraft black liquor," Separation and Purification Technology 51(3), 247-257. DOI: 10.1016/j.seppur.2006.02.005

Boerjan, W., Ralph, J., and Baucher, M. (2003). "Lignin biosynthesis," Annual Review of Plant Biology 54(1), 519-546. DOI: 10.1146/annurev.arplant.54.031902.134938

Braaten, S. M., Christensen, B. E., and Fredheim, G. E. (2003). "Comparison of molecular weight and molecular weight distributions of softwood and hardwood lignosulfonates," Journal of Wood Chemistry and Technology 23(2), 197-215. DOI: 10.1081/WCT-120021925

Braun, J. L., Holtman, K. M., and Kadla, J. F. (2005). "Lignin-based carbon fibers: Oxidative thermostabilization of kraft lignin," Carbon 43(2), 385-394. DOI: 10.1016/j.carbon.204.09.027

Brodin, I., Sjöholm, E., and Gellerstedt, G. (2009). "Kraft lignin as feedstock for chemical products: The effects of membrane filtration," Holzforschung 63(3), 290297. DOI: $10.1515 / \mathrm{HF} .2009 .049$

Brunow, G. (2005). "Methods to reveal the structure of lignin," in: Lignin, Humic Substances and Coal (Biopolymers, Vol. 1), M. Hofrichter, and A. Steinbüchel (eds.), Wiley-VCH, Weinheim, Germany, pp. 89-99.

Brunow, G., Lundquist, K., and Gellerstedt, G. (1998). "Lignin," in: Analytical Methods in Wood Chemistry, Pulping, and Papermaking, E. Sjöström, and R. Alén (eds.), Springer Science and Business Media, New York City, NY, pp. 77-124.

Calvo-Flores, F. G., and Dobado, J. A. (2010). "Lignin as renewable raw material," ChemSusChem 3(11), 1227-1235. DOI: 10.1002/cssc.201000157

Calvo-Flores, F. G., Dobado, J. A., Isac-García, J., and Martín-Martínez, F. J. (2015). Lignin and Lignans as Renewable Raw Materials: Chemistry, Technology and Applications, John Wiley \& Sons, Chichester, UK.

Capanema, E. A., and Balakshin, M. (2014). "High purity lignin, lignin compositions, and higher structured lignin," U. S. Patent No. 2014/0275501.

Capanema, E. A., and Balakshin, M. (2015). "Plantrose lignins: a new type of technical lignins," in: Proceedings of $18^{\text {th }}$ ISWFPC - International Symposium on Wood, Fiber and Pulping Chemistry, Vienna, Austria, pp. 120-123.

Cesarino, I., Araújo, P., Domingues Júnior, A. P., and Mazzafera, P. (2012). “An overview of lignin metabolism and its effect on biomass recalcitrance," Brazilian 
Journal of Botany 35(4), 303-311. DOI: 10.1590/S0100-84042012000400003

Chakar, F. S., and Ragauskas, A. J. (2004). "Review of current and future softwood kraft lignin process chemistry," Industrial Crops and Products 20(2), 131-141. DOI: 10.1016/j.indcrop.2004.04.016

Chatterjee, S., and Saito, T. (2015). "Lignin-derived advanced carbon materials," ChemSusChem 8(23), 3941-3958. DOI: 10.1002/cssc.201500692

Chen, F., Dai, H., Dong, X., Yang, J., and Zhong, M. (2011). "Physical properties of lignin-based polypropylene blends," Polymer Composites 32(7), 1019-1025. DOI: $10.1002 /$ pc. 21087

Chen, Z., Christensen, L., and Dahn, J. R. (2003). "Comparison of PVDF and PVDFTFE-P as binders for electrode materials showing large volume changes in lithiumion batteries," Journal of the Electrochemical Society 150(8), A1073-A1078. DOI: $10.1149 / 1.1586922$

Cheng, S., Yuan, Z., Leitch, M., Anderson, M., and Xu, C. C. (2013). "Highly efficient de-polymerization of organosolv lignin using a catalytic hydrothermal process and production of phenolic resins/adhesives with the depolymerized lignin as a substitute for phenol at a high substitution ratio," Industrial Crops and Products 44, 315-322. DOI: $10.1016 /$ j.indcrop.2012.10.003

Cherubini, F. (2010). "The biorefinery concept: Using biomass instead of oil for producing energy and chemicals," Energy Conversion and Management 51(7), 14121421. DOI: 10.1016/j.enconman.2010.01.015

Cotoruelo, L. M., Marqués, M. D., Díaz, F. J., Rodríguez-Mirasol, J., Rodríguez, J. J., and Cordero, T. (2012a). "Adsorbent ability of lignin-based activated carbons for the removal of p-nitrophenol from aqueous solutions," Chemical Engineering Journal 184, 176-183. DOI: 10.1016/j.cej.2012.01.026

Cotoruelo, L. M., Marqués, M. D., Díaz, F. J., Rodríguez-Mirasol, J., Rodríguez, J. J., and Cordero, T. (2012b). "Lignin-based activated carbons as adsorbents for crystal violet removal from aqueous solutions," Environmental Progress \& Sustainable Energy 31(3), 386-396. DOI: 10.1002/ep.10560

Dai, J., Patti, A. F., and Saito, K. (2016). "Recent developments in chemical degradation of lignin: catalytic oxidation and ionic liquids," Tetrahedron Letters 57(45), 49454951. DOI: 10.1016/j.tetlet.2016.09.084

Dallmeyer, I., Ko, F., and Kadla, J. F. (2010). "Electrospinning of technical lignins for the production of fibrous networks," Journal of Wood Chemistry and Technology 30(4), 315-329. DOI: 10.1080/02773813.2010.527782

Davin, L. B., Jourdes, M., Patten, A. M., Kim, K.-W., Vassão, D. G., and Lewis, N. G. (2008). "Dissection of lignin macromolecular configuration and assembly: comparison to related biochemical processes in allyl/propenyl phenol and lignan biosynthesis," Natural Product Reports 25(6), 1015-1090. DOI: 10.1039/b510386j

Dehne, L., Babarro, C. V., Saake, B., and Schwarz, K. U. (2016). "Influence of lignin source and esterification on properties of lignin-polyethylene blends," Industrial Crops and Products 86, 320-328. DOI: 10.1016/j.indcrop.2016.04.005

del Río, J. C., Lino, A. G., Colodette, J. L., Lima, C. F., Gutiérrez, A., Martínez, Á. T., Lu, F., Ralph, J., and Rencoret, J. (2015). "Differences in the chemical structure of the lignins from sugarcane bagasse and straw," Biomass and Bioenergy, 81, 322-338. DOI: 10.1016/j.biombioe.2015.07.006

del Río, J. C., Rencoret, J., Prinsen, P., Martínez, A. T., Ralph, J., and Gutiérrez, A. (2012). "Structural characterization of wheat straw lignin as revealed by analytical 
pyrolysis, 2D-NMR, and reductive cleavage methods," Journal of Agricultural and Food Chemistry 60(23), 5922-5935. DOI: 10.1021/jf301002n

Dilling, P. (1991). “Sulfonation of lignins," U. S. Patent No. 5.049.661.

Ding, R., Wu, H., Thunga, M., Bowler, N., and Kessler, M. R. (2016). "Processing and characterization of low-cost electrospun carbon fibers from organosolv lignin/ polyacrylonitrile blends," Carbon 100, 126-136. DOI: 10.1016/j.carbon.2015.12.078

Djajadi, D. T., Jensen, M. M., Oliveira, M., Jensen, A., Thygesen, L. G., Pinelo, M., Glasius, M., Jørgensen, H. and Meyer, A. S. (2018). "Lignin from hydrothermally pretreated grass biomass retards enzymatic cellulose degradation by acting as a physical barrier rather than by inducing nonproductive adsorption of enzymes," Biotechnology for Biofuels, 11(1), 85. DOI: 10.1186/s13068-018-1085-0

Doherty, W. O. S., Mousavioun, P., and Fellows, C. M. (2011). "Value-adding to cellulosic ethanol: Lignin polymers," Industrial Crops and Products 33(2), 259-276. DOI: 10.1016/j.indcrop.2010.10.022

dos Santos, P. S. B., Erdocia, X., Gatto, D. A., and Labidi, J. (2014). "Characterisation of kraft lignin separated by gradient acid precipitation," Industrial Crops and Products 55, 149-154. DOI: 10.1016/j.indcrop.2014.01.023

Duval, A., and Lawoko, M. (2014). "A review on lignin-based polymeric, micro- and nano-structured materials," Reactive and Functional Polymers 85, 78-96. DOI: 10.1016/j.reactfunctpolym.2014.09.017

Duval, A., Vilaplana, F., Crestini, C., and Lawoko, M. (2015). "Solvent screening for the fractionation of industrial kraft lignin," Holzforschung 70(1), 11-20. DOI: 10.1515/hf-2014-0346

Effendi, A., Gerhauser, H., and Bridgwater, A. V. (2008). "Production of renewable phenolic resins by thermochemical conversion of biomass: A review," Renewable and Sustainable Energy Reviews 12(8), 2092-2116. DOI: 10.1016/j.rser.2007.04.008

Egüés, I., Sanchez, C., Mondragon, I., and Labidi, J. (2012). "Antioxidant activity of phenolic compounds obtained by autohydrolysis of corn residues," Industrial Crops and Products 36(1), 164-171. DOI: 10.1016/j.indcrop.2011.08.017

Elumalai, S., and Pan, X. J. (2011). "Chemistry and reactions of forest biomass in biorefining," in: Sustainable Production of Fuels, Chemicals, and Fibers from Forest Biomass, J. Y. Jhu, X. Zhang, and X. Pan (eds.), American Chemical Society, Washington, D.C., pp. 109-144.

Fache, M., Boutevin, B., and Caillol, S. (2016). "Vanillin production from lignin and its use as a renewable chemical," ACS Sustainable Chemistry \& Engineering 4(1), 3546. DOI: 10.1021/acssuschemeng.5b01344

Fan, J., and Zhan, H. (2008). "Optimization of synthesis of spherical lignosulphonate resin and its structure characterization," Chinese Journal of Chemical Engineering 16(3), 407-410. DOI: 10.1016/S1004-9541(08)60097-X

Fatehi, P., and Chen, J. (2016). "Extraction of technical lignins from pulping spent liquors, challenges and opportunities," in: Production of Biofuels and Chemicals from Lignin, Z. Fang, and L. Smith (eds.), Springer, Singapore, pp. 35-54.

Fatehi, P., and Ni, Y. (2011). "Integrated forest biorefinery - Sulfite process," in: Sustainable Production of Fuels, Chemicals, and Fibers from Forest Biomass, J. Y. Jhu, X. Zhang, and X. Pan (eds.), American Chemical Society, Washington, D.C., pp. 409-441.

Feng, P., Wang, H., Lin, H., and Zheng, Y. (2019). "Selective production of guaiacol from black liquor: Effect of solvents," Carbon Resources Conversion 2(1), 1-12. 
DOI: $10.1016 / j . c r c o n .2018 .07 .005$

Fierro, V., Torné-Fernández, V., and Celzard, A. (2007). "Methodical study of the chemical activation of kraft lignin with $\mathrm{KOH}$ and $\mathrm{NaOH}$," Microporous and Mesoporous Materials 101(3), 419-431. DOI: 10.1016/j.micromeso.2006.12.004

Filley, T. R., Cody, G. D., Goodell, B., Jellison, J., Noser, C., and Ostrofsky, A. (2002). "Lignin demethylation and polysaccharide decomposition in spruce sapwood degraded by brown rot fungi," Organic Geochemistry 33(2), 111-124. DOI: 10.1016/S0146-6380(01)00144-9

FitzPatrick, M., Champagne, P., Cunningham, M. F., and Whitney, R. A. (2010). “A biorefinery processing perspective: Treatment of lignocellulosic materials for the production of value-added products," Bioresource Technology 101(23), 8915-8922. DOI: 10.1016/j.biortech.2010.06.125

Forss, K., Sagfors P.-E., and Kokkonen R. (1985). "The composition of birch lignin. Fractionation of lignosulfonates and lignosulfonate-carbohydrate compounds," in: Proceedings of International Symposium on Wood and Pulping Chemistry, Vancouver, Canada, pp. 23-26.

Francuskiewicz, F. (1994). "Precipitation fractionation," in: Polymer Fractionation, F. Francuskiewicz (ed.), Springer, Berlin, Heidelberg, Germany, pp. 39-63.

Frank, E., Steudle, L. M., Ingildeev, D., Spoerl, J. M., and Buchmeiser, M. R. (2014). "Carbon fibers: Precursor systems, processing, structure, and properties," Angewandte Chemie International Edition 53(21), 5262-5298. DOI: 10.1002/anie.201306129

Fu, K., Yue, Q., Gao, B., Sun, Y., and Zhu, L. (2013). "Preparation, characterization and application of lignin-based activated carbon from black liquor lignin by steam activation," Chemical Engineering Journal 228, 1074-1082. DOI: 10.1016/j.cej.2013.05.028

Galkin, M. V., and Samec, J. S. (2016). "Lignin valorization through catalytic lignocellulose fractionation: A fundamental platform for the future biorefinery," ChemSusChem 9(13), 1544-1558. DOI: 10.1002/cssc.201600237

Gao, W., Inwood, J. P. W., and Fatehi, P. (2019). "Sulfonation of phenolated kraft lignin to produce water soluble products," Journal of Wood Chemistry and Technology, page nos. to be assigned. DOI: 10.1080/02773813.2019.1565866

Gao, Y. (2017). Biorefinery Lignin as Filler Material in Polylactic Acid Composite, Master's Thesis, Iowa State University, Ames, Iowa, USA.

García, A., Toledano, A., Serrano, L., Egüés, I., González, M., Marín, F., and Labidi, J. (2009). "Characterization of lignins obtained by selective precipitation," Separation and Purification Technology 68(2), 193-198. DOI: 10.1016/j.seppur.2009.05.001

Garcia-Maraver, A., Rodriguez, M. L., Serrano-Bernardo, F., Diaz, L. F., and Zamorano, M. (2015). "Factors affecting the quality of pellets made from residual biomass of olive trees," Fuel Processing Technology 129, 1-7. DOI: 10.1016/j.fuproc.2014.08.018

Gellerstedt, G., and Henriksson, G. (2008). "Lignins: Major sources, structure and properties," in: Monomers, Polymers and Composites from Renewable Resources, M. N. Belgacem, and A. Gandini (eds.), Elsevier, New York, NY, pp. 201-224.

Gellerstedt, G., Tomani, P., Axegard, P., and Backlund, B. (2012). "Lignin recovery and lignin based products," in: Integrated Forest Biorefineries: Challenges and Opportunities, L. Christopher (ed.), Royal Society of Chemistry, Cambridge, UK, pp. $1-66$. 
Ghorbani, M., Liebner, F., van Herwijnen, H. W., Pfungen, L., Krahofer, M., Budjav, E., and Konnerth, J. (2016). "Lignin phenol formaldehyde resoles: The impact of lignin type on adhesive properties," BioResources 11(3), 6727-6741. DOI:

10.15376/biores.11.3.6727-6741

Ghorbani, M., Liebner, F., van Herwijnen, H. W., Solt, P., and Konnerth, J. (2018). "Ligneous resole adhesives for exterior-grade plywood," European Journal of Wood and Wood Products 76(1), 251-258. DOI: 10.1007/s00107-017-1249-9

Gierer, J. (1980). "Chemical aspects of kraft pulping," Wood Science and Technology 14(4), 241-266. DOI: 10.1007/BF00383453

Gierer, J., and Pettersson, I. (1977). "Studies on the condensation of lignins in alkaline media. Part II. The formation of stilbene and arylcoumaran structures through neighbouring group participation reactions," Canadian Journal of Chemistry 55(4), 593-599. DOI: 10.1139/v77-084

Griffini, G., Passoni, V., Suriano, R., Levi, M., and Turri, S. (2015). "Polyurethane coatings based on chemically unmodified fractionated lignin," ACS Sustainable Chemistry \& Engineering 3(6), 1145-1154. DOI: 10.1021/acssuschemeng.5b00073

Gordobil Goñi, O. (2018). New Products from Lignin, Ph.D. Thesis, University of the Basque Country, Spain.

Gordobil Goñi, O., Delucis, R., Egüés, I., and Labidi, J. (2015). "Kraft lignin as filler in PLA to improve ductility and thermal properties," Industrial Crops and Products 72, 46-53. DOI: 10.1016/j.indcrop.2015.01.055

Goring, D. A. (1971). "Polymer properties of lignin and lignin derivatives," in: Lignins: Occurrence, Formation, Structure and Reactions, K. V. Sarkanen, and C. H. Ludwig (eds.), John Wiley \& Sons, New York, NY, pp. 695-768.

Gustafsson, A., Hale, S., Cornelissen, G., Sjöholm, E., and Gunnarsson, J. S. (2017). "Activated carbon from kraft lignin: A sorbent for in situ remediation of contaminated sediments," Environmental Technology \& Innovation 7, 160-168. DOI: 10.1016/j.eti.2016.11.001

Hajirahimkhan, S., Ragogna, P. J., and Xu, C. C. (2019). "Methacrylation of kraft lignin for UV-curable coatings: Process optimization using response surface methodology," Biomass and Bioenergy 120, 332-338. DOI: 10.1016/j.biombioe.2018.11.038

Hayashi, J. I., Kazehaya, A., Muroyama, K., and Watkinson, A. P. (2000). "Preparation of activated carbon from lignin by chemical activation," Carbon 38(13), 1873-1878. DOI: 10.1016/S0008-6223(00)00027-0

He, W., and Fatehi, P. (2015). "Preparation of sulfomethylated softwood kraft lignin as a dispersant for cement admixture," RSC Advances 5(58), 47031-47039. DOI: 10.1039/C5RA04526F

Heden, S., and Holmberg, B. (1936). "Bisulfitkok med aromatiska alkoholer [Bisulfite with aromatic alcohols]," Svensk Kemisk Tidskrift 48, 207-211.

Helander, M., Theliander, H., Lawoko, M., Henriksson, G., Zhang, L., and Lindström, M. E. (2013). "Fractionation of technical lignin: Molecular mass and $\mathrm{pH}$ effects," BioResources 8(2), 2270-2282. DOI: 10.15376/biores.8.2.2270-2282

Hosseinaei, O., Harper, D. P., Bozell, J. J., and Rials, T. G. (2016). "Role of physicochemical structure of organosolv hardwood and herbaceous lignins on carbon fiber performance," ACS Sustainable Chemistry \& Engineering 4(10), 5785-5798. DOI: 10.1021/acssuschemeng.6b01828

Hu, J., Zhang, Q., and Lee, D. J. (2018). "Kraft lignin biorefinery: A perspective," Bioresource Technology 247, 1181-1183. DOI: 10.1016/j.biortech.2017.08.169 
Hu, L., Pan, H., Zhou, Y., and Zhang, M. (2011). "Methods to improve lignin's reactivity as a phenol substitute and as replacement for other phenolic compounds: A brief review," BioResources 6(3), 3515-3525.

Huang, C., He, J., Chang, H.-M., Jameel, H., and Yong, Q. (2017). “Coproduction of ethanol and lignosulfonate from moso bamboo residues by fermentation and sulfomethylation," Waste and Biomass Valorization 8(3), 965-974. DOI: 10.1007/s12649-016-9629-7

Huang, C., Ma, J., Zhang, W., Huang, G., and Yong, Q. (2018). “Preparation of lignosulfonates from biorefinery lignins by sulfomethylation and their application as a water reducer for concrete," Polymers 10(8), 841. DOI: 10.3390/polym10080841

Huang, X. (2009). "Fabrication and properties of carbon fibers," Materials 2(4), 23692403. DOI: $10.3390 / \mathrm{ma} 2042369$

Huber, G. W., Iborra, S., and Corma, A. (2006). "Synthesis of transportation fuels from biomass: chemistry, catalysts, and engineering," Chemical Reviews 106(9), 40444098. DOI: $10.1021 / \mathrm{cr} 068360 \mathrm{~d}$

Hult, E.-L., Ropponen, J., Poppius-Levlin, K., Ohra-Aho, T., and Tamminen, T. (2013). "Enhancing the barrier properties of paper board by a novel lignin coating," Industrial Crops and Products 50, 694-700. DOI: 10.1016/j.indcrop.2013.08.013

Inwood, J. (2014). Sulfonation of Kraft Lignin to Water Soluble Value Added Products, Master's Thesis, Lakehead University, Thunder Bay, Ontario, Canada.

Jääskeläinen, A. S., Willberg-Keyriläinen, P., Liitiä, T., and Tamminen, T. (2017). "Carbohydrate-free and highly soluble softwood kraft lignin fractions by aqueous acetone evaporation fractionation," Nordic Pulp and Paper Research Journal 32(4), 485-492. DOI: 10.3183/npprj-2017-32-04_p485-492_jaaskelainen

Jeong, H., Park, J., Kim, S., Lee, J., and Cho, J. W. (2012). "Use of acetylated softwood kraft lignin as filler in synthetic polymers," Fibers and Polymers 13(10), 1310-1318. DOI: $10.1007 / \mathrm{s} 12221-012-1310-6$

Jiang, X., Liu, J., Du, X., Hu, Z., Chang, H.-M., and Jameel, H. (2018). "Phenolation to improve lignin reactivity toward thermosets application," ACS Sustainable Chemistry \& Engineering 6(4), 5504-5512. DOI: 10.1021/acssuschemeng.8b00369

Jönsson, A.-S., Nordin, A.-K., and Wallberg, O. (2008). "Concentration and purification of lignin in hardwood kraft pulping liquor by ultrafiltration and nanofiltration," Chemical Engineering Research and Design 86(11), 1271-1280. DOI: 10.1016/j.cherd.2008.06.003

Kabir, A. S. (2017). Effects of Lignin as a Stabilizer or Antioxidant in Polyolefins, Master's Thesis, University of Western Ontario, London, Ontario, Canada.

Kadla, J. F., and Kubo, S. (2004). "Lignin-based polymer blends: Analysis of intermolecular interactions in lignin-synthetic polymer blends," Composites Part A: Applied Science and Manufacturing 35(3), 395-400. DOI:

10.1016/j.compositesa.2003.09.019

Kadla, J. F., Kubo, S., Venditti, R. A., Gilbert, R. D., Compere, A. L., and Griffith, W. (2002). "Lignin-based carbon fibers for composite fiber applications," Carbon 40(15), 2913-2920. DOI: 10.1016/S0008-6223(02)00248-8

Kalliola, A. K., Savolainen, A., Ohra-aho, T., Faccio, G., and Tamminen, T. (2012). "Reducing the content of VOCs of softwood kraft lignins for material applications," BioResources 7(3), 2871-2882. DOI: 15376/biores.7.3.2871-2882

Kalogiannis, K. G., Stefanidis, S. D., Michailof, C. M., Lappas, A. A., and Sjöholm, E. (2015). "Pyrolysis of lignin with 2DGC quantification of lignin oil: Effect of lignin 
type, process temperature and ZSM-5 in situ upgrading," Journal of Analytical and Applied Pyrolysis 115, 410-418. DOI: 10.1016/j.jaap.2015.08.021

Kamoun, A., Jelidi, A., and Chaabouni, M. (2003). "Evaluation of the performance of sulfonated esparto grass lignin as a plasticizer-water reducer for cement," Cement and Concrete Research 33(7), 995-1003. DOI: 10.1016/S0008-8846(02)01098-0

Kim, J.-Y., Park, J., Hwang, H., Kim, J. K., Song, I. K., and Choi, J. W. (2015). "Catalytic depolymerization of lignin macromolecule to alkylated phenols over various metal catalysts in supercritical tert-butanol," Journal of Analytical and Applied Pyrolysis 113, 99-106. DOI: 10.1016/j.jaap.2014.11.011

Klein, S. E., Rumpf, J., Kusch, P., Albach, R., Rehahn, M., Witzleben, S., and Schulze, M. (2018). "Unmodified kraft lignin isolated at room temperature from aqueous solution for preparation of highly flexible transparent polyurethane coatings," RSC Advances 8(71), 40765-40777. DOI: 10.1039/c8ra08579j

Kleinhans, H., and Salmén, L. (2016). "Development of lignin carbon fibers: Evaluation of the carbonization process," Journal of Applied Polymer Science 133(38). DOI: 10.1002/app.43965

Klemm, D., Schmauder, H. P., and Heinze, T. (2002). “Cellulose,” in: Biopolymers: Biology, Chemistry, Biotechnology, Applications, E. J. Vandamme, S. Baets, and A. Steinbőchel (eds.), Wiley-Blackwell, New York, NY, pp. 277-319.

Konduri, M. K., and Fatehi, P. (2015). "Production of water-soluble hardwood kraft lignin via sulfomethylation using formaldehyde and sodium sulfite," ACS Sustainable Chemistry \& Engineering 3(6), 1172-1182. DOI: 10.1021/acssuschemeng.5b00098

Krotscheck, A., and Sixta, H. (2006). "Recovery," in: Handbook of Pulp, H. Sixta (ed.) Wiley-VCH, Weinheim, Alemanha, Germany, pp. 967-998.

Kubo, S., and Kadla, J. F. (2005). "Lignin-based carbon fibers: Effect of synthetic polymer blending on fiber properties," Journal of Polymers and the Environment 13(2), 97-105. DOI: 10.1007/s10924-005-2941-0

Kun, D., and Pukánszky, B. (2017). "Polymer/lignin blends: Interactions, properties, applications," European Polymer Journal 93, 618-641. DOI:

10.1016/j.eurpolymj.2017.04.035

Kvarnlöf, N., and Germgård, U. (2015). "Oxygen delignification of acid sulfite and bisulfite softwood pulps," BioResources 10(3), 3934-3947. DOI:

10.15376/biores.10.3.3934-3947

Laurichesse, S., and Avérous, L. (2014). "Chemical modification of lignins: Towards biobased polymers," Progress in Polymer Science 39(7), 1266-1290. DOI: 10.1016/j.progpolymsci.2013.11.004

Leppävuori, J., Wikberg, H., Ohra-Aho, T., Kanerva, H., and Liitiä, T. (2017). "CatLignin - Reactive lignin for wood adhesives," in: Proceedings of $19^{\text {th }}$ International Symposium on Wood, Fibre and Pulping Chemistry, Porto Seguro, Bahia, Brazil, pp. 137-141.

Li, H., and McDonald, A. G. (2014). "Fractionation and characterization of industrial lignins," Industrial Crops and Products 62, 67-76. DOI: 10.1016/j.indcrop.2014.08.013

Li, J., Wang, M., She, D., and Zhao, Y. (2017b). "Structural functionalization of industrial softwood kraft lignin for simple dip-coating of urea as highly efficient nitrogen fertilizer," Industrial Crops and Products 109, 255-265. DOI: 10.1016/j.indcrop.2017.08.011

Li, K., and Geng, X. (2005). "Formaldehyde-free wood adhesives from decayed 
wood," Macromolecular Rapid Communications 26(7), 529-532. DOI:

10.1002/marc.200400594

Li, Q., Xie, S., Serem, W. K., Naik, M. T., Liu, L., and Yuan, J. S. (2017). “Quality carbon fibers from fractionated lignin," Green Chemistry 19(7), 1628-1634. DOI: 10.1039/C6GC03555H

Li, X. F., Xu, Q., Fu, Y., and Guo, Q.-X. (2014a). "Preparation and characterization of activated carbon from kraft lignin via $\mathrm{KOH}$ activation," Environmental Progress \& Sustainable Energy 33(2), 519-526. DOI: 10.1002/ep.11794

Li, X., and Luo, X. (2013). "Preparation of mesoporous activated carbon from kraft lignin by impregnation with $\mathrm{H}_{2} \mathrm{SO}_{4}$ : A four parameters optimization study," Environmental Progress \& Sustainable Energy 32(4), 1158-1163. DOI: 10.1002/ep.11716

Li, Z., and Ge, Y. (2011). "Extraction of lignin from sugar cane bagasse and its modification into a high performance dispersant for pesticide formulations," Journal of the Brazilian Chemical Society 22(10), 1866-1871. DOI: 10.1590/S010350532011001000006

Lin, S. Y., and Dence, C. W. (1992). “Commercial spent pulping liquors,” in: Methods in Lignin Chemistry, D. Meier, and O. Faix (eds.), Springer, New York, NY, pp. 75-80.

Liu, C. J. (2012). "Deciphering the enigma of lignification: Precursor transport, oxidation, and the topochemistry of lignin assembly," Molecular Plant 5(2), 304-317. DOI: $10.1093 / \mathrm{mp} / \mathrm{ssr} 121$

Liu, H. C., Chien, A.-T., Newcomb, B. A., Davijani, A. A. B., and Kumar, S. (2016). "Stabilization kinetics of gel spun polyacrylonitrile/lignin blend fiber," Carbon 101, 382-389. DOI: 10.1016/j.carbon.2016.01.096

Lora, J. (2008). "Industrial commercial lignins: Sources, properties and applications," in: Monomers, Polymers and Composites from Renewable Resources, M. N. Belgacem, and A. Gandini (eds.), Elsevier, New York, NY, pp. 225-241.

Lu, H., Cornell, A., Alvarado, F., Behm, M., Leijonmarck, S., Li, J., Tomani, P., and Lindbergh, G. (2016). "Lignin as a binder material for eco-friendly Li-ion batteries," Materials 9(3), E127. DOI: 10.3390/ma9030127

Lu, Q., Liu, W., Yang, L., Zu, Y., Zu, B., Zhu, M., Zhang, Y., Zhang, X., Zhang, R., Sun, Z., et al. (2012). "Investigation of the effects of different organosolv pulping methods on antioxidant capacity and extraction efficiency of lignin," Food Chemistry 131(1), 313-317. DOI: 10.1016/j.foodchem.2011.07.116

Macfarlane, A. L., Prestidge, R., Farid, M. M., and Chen, J. J. J. (2009). "Dissolved air flotation: A novel approach to recovery of organosolv lignin," Chemical Engineering Journal 148(1), 15-19. DOI: 10.1016/j.cej.2008.07.036

Mahmood, N., Yuan, Z., Schmidt, J., and Xu, C. C. (2013). "Production of polyols via direct hydrolysis of kraft lignin: Effect of process parameters," Bioresource Technology 139, 13-20. DOI: 10.1016/j.biortech.2013.03.199

Mainka, H., Täger, O., Körner, E., Hilfert, L., Busse, S., Edelmann, F. T., and Herrmann, A. S. (2015). "Lignin-An alternative precursor for sustainable and cost-effective automotive carbon fiber," Journal of Materials Research and Technology 4(3), 283296. DOI: 10.1016/j.jmrt.2015.03.004

Maldhure, A. V., Chaudhari, A. R., and Ekhe, J. D. (2011). "Thermal and structural studies of polypropylene blended with esterified industrial waste lignin," J. Thermal Analysis and Calorimetry 103(2), 625-632. DOI: 10.1007/s10973-010-1048-6 Maldhure, A. V., Ekhe, J. D., and Deenadayalan, E. (2012). "Mechanical properties of 
polypropylene blended with esterified and alkylated lignin," Journal of Applied Polymer Science 125(3), 1701-1712. DOI: 10.1002/app.35633

Malutan, T., Nicu, R., and Popa, V. I. (2007). "Contribution to the study of hydroxymethylation reaction of alkali lignin," BioResources 3(1), 13-20. DOI: 10.15376/biores.3.1.13-20

Mao, J. Z., Zhang, L. M., and Xu, F. (2012). "Fractional and structural characterization of alkaline lignins from Carex meyeriana Kunth," Cellulose Chemistry and Technology 46(3), 193-205.

Mašura, V. (1982). "Alkaline degradation of spruce and beech wood," Wood Science and Technology 16(2), 155-164. DOI: 10.1007/BF00351100

Matsushita, Y. (2015). "Conversion of technical lignins to functional materials with retained polymeric properties," Journal of Wood Science 61(3), 230-250. DOI: $10.1007 / \mathrm{s} 10086-015-1470-2$

Matsushita, Y., and Yasuda, S. (2005). "Preparation and evaluation of lignosulfonates as a dispersant for gypsum paste from acid hydrolysis lignin," Bioresource Technology 96(4), 465-470. DOI: 10.1016/j.biortech.2004.05.023

Meek, N., Penumadu, D., Hosseinaei, O., Harper, D., Young, S., and Rials, T. (2016). "Synthesis and characterization of lignin carbon fiber and composites," Composites Science and Technology 137, 60-68. DOI: 10.1016/j.compscitech.2016.10.016

Merker, G. P., Schwarz, C., and Teichmann, R. (2011). Combustion Engines Development: Mixture Formation, Combustion, Emissions and Simulation, Springer Science \& Business Media, New York, NY.

Mohan, D., Pittman Jr., C. U., and Steele, P. H. (2006). "Single, binary and multicomponent adsorption of copper and cadmium from aqueous solutions on kraft lignin-A biosorbent," Journal of Colloid and Interface Science 297(2), 489-504. DOI: 10.1016/j.jcis.2005.11.023

Mulder, W. J., Gosselink, R. J. A., Vingerhoeds, M. H., Harmsen, P. F. H., and Eastham, D. (2011). "Lignin based controlled release coatings," Industrial Crops and Products 34(1), 915-920. DOI: 10.1016/j.indcrop.2011.02.011

Nanayakkara, B., Manley-Harris, M., Suckling, I. D., and Donaldson, L. A. (2009). "Quantitative chemical indicators to assess the gradation of compression wood," Holzforschung 63(4), 431-439. DOI: 10.1515/HF

Nandanwar, R. A., Chaudhari, A. R., and Ekhe, J. D. (2016). "Nitrobenzene oxidation for isolation of value added products from industrial waste lignin," Journal of Chemical, Biological and Physical Sciences 6, 501-513.

Naseem, A., Tabasum, S., Zia, K. M., Zuber, M., Ali, M., and Noreen, A. (2016). "Lignin-derivatives based polymers, blends and composites: A review," International Journal of Biological Macromolecules 93(Part A), 296-313. DOI: 10.1016/j.ijbiomac.2016.08.030

Nenkova, S., Vasileva, T., and Stanulov, K. (2008). "Production of phenol compounds by alkaline treatment of technical hydrolysis lignin and wood biomass," Chemistry of Natural Compounds 44(2), 182-185. DOI: 10.1007/s10600-008-9009-z

Nirmale, T. C., Kale, B. B., and Varma, A. J. (2017). "A review on cellulose and lignin based binders and electrodes: Small steps towards a sustainable lithium ion battery," International Journal of Biological Macromolecules 103, 1032-1043. DOI: 10.1016/j.ijbiomac.2017.05.155

Norberg, I. (2012). Carbon Fibres from Kraft Lignin, Ph.D. Thesis, KTH Royal Institute of Technology, Stockholm, Sweden. 
Norberg, I., Nordström, Y., Drougge, R., Gellerstedt, G., and Sjöholm, E. (2013). "A new method for stabilizing softwood kraft lignin fibers for carbon fiber production," Journal of Applied Polymer Science 128(6), 3824-3830. DOI: 10.1002/app.38588

Nordström, Y., Norberg, I., Sjöholm, E., and Drougge, R. (2013). "A new softening agent for melt spinning of softwood kraft lignin," Journal of Applied Polymer Science 129(3), 1274-1279. DOI: 10.1002/app.38795

Norgren, M., and Edlund, H. (2014). "Lignin: Recent advances and emerging applications," Current Opinion in Colloid \& Interface Science 19(5), 409-416. DOI: 10.1016/j.cocis.2014.08.004

Norgren, M., and Lindström, B. (2000). "Dissociation of phenolic groups in kraft lignin at elevated temperatures," Holzforschung 54(5), 519-527. DOI: 10.1515/HF.2000.088

Notley, S. M., and Norgren, M. (2009) "Lignin: Functional biomaterial with potential in surface chemistry and nanoscience," in: The Nanoscience and Technology of Renewable Biomaterials, L. A. Lucia, and O. J. Rojas (eds.), Wiley-Blackwell, Chichester, UK, pp. 173-205.

Öhman, F., Wallmo, H., and Theliander, H. (2007). "A novel method for washing lignin precipitated form kraft black liquor - Laboratory trials," Nordic Pulp and Paper Research Journal 22(1), 9-16. DOI: 10.3183/NPPRJ-2007-22-01-p009-016

Okamoto, T., Takeda, H., Funabiki, T., Takatani, M., and Hamada, R. (1996). "Fundamental studies on the development of lignin-based adhesives, I. Catalytic demethylation of anisole with molecular oxygen," Reaction Kinetics and Catalysis Letters 58(2), 237-242. DOI: 10.1007/BF02067028

Ouyang, X., Ke, L., Qiu, X., Guo, Y., and Pang, Y. (2009). "Sulfonation of alkali lignin and its potential use in dispersant for cement," Journal of Dispersion Science and Technology 30(1), 1-6. DOI: 10.1080/01932690802473560

Pacek, A. W., Ding, P., Garrett, M., Sheldrake, G., and Nienow, A. W. (2013). "Catalytic conversion of sodium lignosulfonate to vanillin: engineering aspects. Part 1. Effects of processing conditions on vanillin yield and selectivity," Industrial \& Engineering Chemistry Research 52(25), 8361-8372. DOI: 10.1021/ie4007744

Pan, X., Kadla, J. F., Ehara, K., Gilkes, N., and Saddler, J. N. (2006). “Organosolv ethanol lignin from hybrid poplar as a radical scavenger: Relationship between lignin structure, extraction conditions, and antioxidant activity," Journal of Agricultural and Food Chemistry 54(16), 5806-5813. DOI: 10.1021/jf0605392

Pandey, M. P., and Kim, C. S. (2011). "Lignin depolymerization and conversion: A review of thermochemical methods," Chemical Engineering \& Technology 34(1), 2941. DOI: 10.1002/ceat.201000270

Park, S. Y., Kim, J. Y., Youn, H. J., and Choi, J. W. (2018). "Fractionation of lignin macromolecules by sequential organic solvents systems and their characterization for further valuable applications," International Journal of Biological Macromolecules 106, 793-802. DOI: 10.1016/j.ijbiomac.2017.08.069

Pinto, P. C. R., Da Silva, E. A. B., and Rodrigues, A. E. (2012) "Lignin as source of fine chemicals: Vanillin and syringaldehyde," in: Biomass Conversion, C. Baskar, S. Baskar, R. S. Dhillon (eds.), Springer, Berlin, Germany, pp. 381-420.

Pinto, P. C., Evtuguin, D. V., and Pascoal Neto, C. (2005). "Effect of Structural features of wood biopolymers on hardwood pulping and bleaching performance," Industrial \& Engineering Chemistry Research 44(26), 9777-9784. DOI: 10.1021/ie050760o

Ponnusamy, V. K., Nguyen, D. D., Dharmaraja, J., Shobana, S., Banu, R., Saratale, R. G., Chang, S. H., and Kumar, G. (2019). "A review on lignin structure, pretreatments, 
fermentation reactions and biorefinery potential," Bioresource Technology 271, 462472. DOI: 10.1016/j.biortech.2018.09.070

Potthast, A. (2006). "Chemistry of kraft cooking," in: Handbook of Pulp, H. Sixta (ed.) Wiley-VCH, Weinheim, Alemanha, Germany, pp. 164-185.

Puziy, A. M., Poddubnaya, O. I., and Sevastyanova, O. (2018). "Carbon materials from technical lignins: Recent advances," Topics in Current Chemistry 376(4), 33. DOI: 10.1007/s41061-018-0210-7

Ragan, S., and Megonnell, N. (2011). "Activated carbon from renewable resourcesLignin," Cellulose Chemistry and Technology 45(7), 527-531.

Ragauskas, A. J., Beckham, G. T., Biddy, M. J., Chandra, R., Chen, F., Davis, M. F., Davison, B. H., Dixon, R. A., Gilna, P., Keller, M. Langan, P., et al. (2014). "Lignin valorization: Improving lignin processing in the biorefinery," Science 344(6185), 1246843. DOI: $10.1126 /$ science. 1246843

Ragnar, M., Lindgren, C. T., and Nilvebrant, N. O. (2000). "pKa-Values of guaiacyl and syringyl phenols related to lignin," Journal of Wood Chemistry and Technology 20(3), 277-305. DOI: 10.1080/02773810009349637

Reeve, D. W. (2002). “The kraft recovery cycle," in: Tappi Kraft Recovery Operations Short Course, Tappi Press, Atlanta, GA, pp. 1-16.

Rodríguez-Mirasol, J., Cordero, T., and Rodríguez, J. J. (1993a). "Preparation and characterization of activated carbons from eucalyptus kraft lignin," Carbon 31(1), 8795. DOI: 10.1016/0008-6223(93)90160-C

Rodríguez-Mirasol, J., Cordero, T., and Rodriguez, J. J. (1993b). “Activated carbons from carbon dioxide partial gasification of eucalyptus kraft lignin," Energy \& Fuels 7(1), 133-138. DOI: 10.1021/ef00037a021

Roopan, S. M. (2017). "An overview of natural renewable bio-polymer lignin towards nano and biotechnological applications," International Journal of Biological Macromolecules 103, 508-514. DOI: 10.1016/j.ijbiomac.2017.05.103

Rosas, J. M., Bedia, J., Rodríguez-Mirasol, J., and Cordero, T. (2010). "On the preparation and characterization of chars and activated carbons from orange skin," Fuel Processing Technology 91(10), 1345-1354. DOI:

10.1016/j.fuproc.2010.05.006

Rosas, J. M., Berenguer, R., Valero-Romero, M. J., Rodríguez-Mirasol, J., and Cordero, T. (2014). "Preparation of different carbon materials by thermochemical conversion of lignin," Frontiers in Materials 1, 29. DOI: 10.3389/fmats.2014.00029

Rößiger, B., Unkelbach, G., and Pufky-Heinrich, D. (2018). "Base-catalyzed depolymerization of lignin: History, challenges and perspectives," in: Lignin-Trends and Applications, M. Poletto (ed.), InTechOpen, Rijeka, Croatia, pp. 99-120.

Rudatin, S., Sen, Y. L., and Woerner, D. L. (1989). "Association of kraft lignin in aqueous solution," in: Lignin: Properties and Materials, W. G. Glasser, and S. Sarkanen (eds.), American Chemical Society, Washington, D.C., pp. 144-154.

Sevastyanova, O., Qin, W., and Kadla, J. F. (2010). "Effect of nanofillers as reinforcement agents for lignin composite fibers," Journal of Applied Polymer Science 117(5), 2877-2881. DOI: 10.1002/app.32198

Siddiqui, H. (2013). Production of Lignin-Based Phenolic Resins Using Depolymerized Kraft Lignin and Process Optimization, Master's Thesis, University of Western Ontario, London, Ontario, Canada.

Siddiqui, H., Mahmood, N., Yuan, Z., Crapulli, F., Dessbesell, L., Rizkalla, A., Ray, A., and $\mathrm{Xu}, \mathrm{C}$. C. (2017). "Sustainable bio-based phenol-formaldehyde resoles using 
hydrolytically depolymerized kraft lignin," Molecules 22(11), E1850. DOI:

10.3390/molecules22111850

Sjöström, E. (1993). Wood Chemistry: Fundamentals and Applications, Academic Press Inc., San Diego, CA.

Smook, G. A. (2002). Handbook for Pulp and Paper Technologies, Angus Wilde Publications Inc., Vancouver, British Columbia, Canada, 425.

Snowdon, M. R., Mohanty, A. K., and Misra, M. (2014). "A study of carbonized lignin as an alternative to carbon black," ACS Sustainable Chemistry \& Engineering 2(5), 1257-1263. DOI: $10.1021 / \mathrm{sc} 500086 \mathrm{v}$

Soile, O. O. B., and Owoyokun, T. O. (2014). “Oil production from kraft lignin via thermochemical liquefaction using $\mathrm{Ru} / \mathrm{Al}_{\mathrm{y}}\left(\mathrm{SiO}_{4}\right)_{\mathrm{x}}$ catalyst," International Journal of Biomass \& Renewables 3(2), 1-11. DOI:

Solt, P., Jääskeläinen, A. S., Lingenfelter, P., Konnerth, J., and van Herwijnen, H. W. G. (2018b). "Impact of molecular weight of kraft-lignin on adhesive performance of lignin based phenol formaldehyde resins," Forest Products Journal 68(4), 365-371. DOI: 10.13073/FPJ-D-17-00079

Solt, P., Rößiger, B., Konnerth, J., and van Herwijnen, H. (2018a). "Lignin phenol formaldehyde resoles using base-catalysed depolymerized kraft lignin," Polymers 10(10), 1162. DOI: 10.3390/polym10101162

Spiridon, I., Leluk, K., Resmerita, A. M., and Darie, R. N. (2015). "Evaluation of PLAlignin bioplastics properties before and after accelerated weathering," Composites Part B: Engineering 69, 342-349. DOI: 10.1016/j.compositesb.2014.10.006

Stewart, D. (2008). "Lignin as a base material for materials applications: Chemistry, application and economics," Industrial Crops and Products 27(2), 202-207. DOI: 10.1016/j.indcrop.2007.07.008

Sudo, K., and Shimizu, K. (1992). “A new carbon fiber from lignin,” Journal of Applied Polymer Science 44(1), 127-134. DOI: 10.1002/app.1992.070440113

Sudo, K., Shimizu, K., Nakashima, N., and Yokoyama, A. (1993). “A new modification method of exploded lignin for the preparation of a carbon fiber precursor," Journal of Applied Polymer Science 48(8), 1485-1491. DOI: 10.1002/app.1993.070480817

Suhas, Carrott, P. J. M., and Carrott, M. R. (2007). "Lignin-From natural adsorbent to activated carbon: A review," Bioresource Technology 98(12), 2301-2312. DOI: 10.1016/j.biortech.2006.08.008

Sundin, J. (2000). Precipitation of Kraft Lignin Under Alkaline Conditions, Ph.D. Thesis, Royal Institute of Technology, Stockholm, Sweden.

Supanchaiyamat, N., Jetsrisuparb, K., Knijnenburg, J. T. N., Tsang, D. C. W., and Hunt, A. J. (2019). "Lignin materials for adsorption: Current trend, perspectives and opportunities," Bioresource Technology 272, 570-581. DOI: 10.1016/j.biortech.2018.09.139

Tarabanko, V., and Tarabanko, N. (2017). "Catalytic oxidation of lignins into the aromatic aldehydes: General process trends and development prospects," International Journal of Molecular Sciences 18(11), E2421. DOI: 10.3390/ijms 18112421

Tejado, A., Pena, C., Labidi, J., Echeverria, J. M., and Mondragon, I. (2007). "Physicochemical characterization of lignins from different sources for use in phenolformaldehyde resin synthesis," Bioresource Technology 98(8), 1655-1663. DOI: 10.1016/j.biortech.2006.05.042

Thakur, V. K., Thakur, M. K., Raghavan, P., and Kessler, M. R. (2014). "Progress in 
green polymer composites from lignin for multifunctional applications: A review," ACS Sustainable Chemistry \& Engineering 2(5), 1072-1092. DOI: $10.1021 / \mathrm{sc} 500087 \mathrm{z}$

Theliander, H. (2008). "Withdrawing lignin from black liquor by precipitation, filtration and washing," in: Proceedings of Nordic Wood Biorefinery Conference, Stockholm, Sweden, pp. 36-42.

Thunga, M., Chen, K., Grewell, D., and Kessler, M. R. (2014). "Bio-renewable precursor fibers from lignin/polylactide blends for conversion to carbon fibers," Carbon 68, 159-166. DOI: 10.1016/j.carbon.2013.10.075

Tian, D., Hu, J., Bao, J., Chandra, R. P., Saddler, J. N., and Lu, C. (2017). "Lignin valorization: Lignin nanoparticles as high-value bio-additive for multifunctional nanocomposites," Biotechnology for Biofuels 10, 192. DOI: 10.1186/s13068-0170876-z

Titirici, M.-M., White, R. J., Brun, N., Budarin, V. L., Su, D. S., del Monte, F., Clark, J. H., and MacLachlan, M. J. (2015). "Sustainable carbon materials," Chemical Society Reviews 44(1), 250-290. DOI: 10.1039/c4cs00232f

Toledano, A., García, A., Mondragon, I., and Labidi, J. (2010). "Lignin separation and fractionation by ultrafiltration," Separation and Purification Technology 71(1), 3843. DOI: $10.1016 /$ j.seppur.2009.10.024

Tomani, P. (2010). "The lignoboost process," Cellulose Chemistry and Technology 44(1), 53.

Tran, H., and Vakkilainen, E. (2008). "The kraft chemical recovery process," in: Tappi Kraft Pulping Short Course, Tappi Press, St. Petersburg, FL, USA, pp. 1-8.

Ugartondo, V., Mitjans, M., and Vinardell, M. P. (2008). "Comparative antioxidant and cytotoxic effects of lignins from different sources," Bioresource Technology 99(14), 6683-6687. DOI: 10.1016/j.biortech.2007.11.038

Uraki, Y., Nakatani, A., Kubo, S., and Sano, Y. (2001). "Preparation of activated carbon fibers with large specific surface area from softwood acetic acid lignin," Journal of Wood Science 47(6), 465-469. DOI: 10.1007/BF00767899

Vainio, U., Maximova, N., Hortling, B., Laine, J., Stenius, P., Simola, L. K., Gravitis, J., and Serimaa, R. (2004). "Morphology of dry lignins and size and shape of dissolved kraft lignin particles by X-ray scattering," Langmuir 20(22), 9736-9744. DOI: $10.1021 / \mathrm{la} 048407 \mathrm{v}$

Valmet - Technical Papers Series (2017). "The next generation LignoBoost - Tailor-maid lignin production for different lignin bioproduct markets," (https://www.valmet.com/globalassets/media/downloads/white-papers/power-andrecovery/next_generation_lignoboost_whitepaper.pdf.) Accessed 12 January 2019.

Vanholme, R., Demedts, B., Morreel, K., Ralph, J., and Boerjan, W. (2010). "Lignin biosynthesis and structure," Plant Physiology 153(3), 895-905. DOI: $10.1104 / p p .110 .155119$

Verma, D., Singla, A., Lal, B., and Sarma, P. M. (2016). "Conversion of biomassgenerated syngas into next-generation liquid transport fuels through microbial intervention: Potential and current status," Current Science 110(3), 329-336. DOI: $10.18520 / \mathrm{cs} / \mathrm{v} 110 / \mathrm{i} 3 / 329-336$

Vila, C., Santos, V., Saake, B., and Parajó, J. C. (2016). "Manufacture, characterization, and properties of poly-(lactic acid) and its blends with esterified pine lignin," BioResources 11(2), 5322-5332. DOI: 10.15376/biores.11.2.5322-5332

Vishtal, A. G., and Kraslawski, A. (2011). "Challenges in industrial applications of 
technical lignins," BioResources 6(3), 3547-3568. DOI: 10.15376/biores.6.3.35473568

Wahyudiono, Sasaki, M., and Goto, M. (2008). "Recovery of phenolic compounds through the decomposition of lignin in near and supercritical water," Chemical Engineering and Processing: Process Intensification 47(9-10), 1609-1619. DOI: 10.1016/j.cep.2007.09.001

Wallberg, O., Jönsson, A.-S., and Wimmerstedt, R. (2003). "Ultrafiltration of kraft black liquor with a ceramic membrane," Desalination 156(1-3), 145-153. DOI:

10.1016/S0011-9164(03)00337-0

Wang, G., and Chen, H. (2013). "Fractionation of alkali-extracted lignin from steamexploded stalk by gradient acid precipitation," Separation and Purification Technology 105, 98-105. DOI: 10.1016/j.seppur.2012.12.009

Wang, H. M., Wang, B., Wen, J.-L., Yuan, T.-Q., and Sun, R.-C. (2017). "Structural characteristics of lignin macromolecules from different Eucalyptus species," ACS Sustainable Chemistry \& Engineering 5(12), 11618-11627. DOI: 10.1021/acsuschemeng.7b02970

Wang, H., de Vries Frits, P., and Jin, Y. (2009). "A win-win technique of stabilizing sand dune and purifying paper mill black-liquor," Journal of Environmental Sciences 21(4), 488-493. DOI: 10.1016/S1001-0742(08)62296-2

Wang, H., Pu, Y., Ragauskas, A., and Yang, B. (2019). "From lignin to valuable products-Strategies, challenges and prospects," Bioresource Technology 271, 449461. DOI: 10.1016/j.biortech.2018.09.072

Wang, H., Tucker, M., and Ji, Y. (2013). "Recent development in chemical depolymerization of lignin: A review," Journal of Applied Chemistry 2013, 1-9. DOI: $10.1155 / 2013 / 838645$

Wang, S., Zhou, Z., Xiang, H., Chen, W., Yin, E., Chang, T., and Zhu, M. (2016). "Reinforcement of lignin-based carbon fibers with functionalized carbon nanotubes," Composites Science and Technology 128, 116-122. DOI: 10.1016/j.compscitech.2016.03.018

Wang, Y., Sun, S., Li, F., Cao, X., and Sun, R. (2018). "Production of vanillin from lignin: The relationship between $\beta-\mathrm{O}-4$ linkages and vanillin yield," Industrial Crops and Products 116, 116-121. DOI: 10.1016/j.indcrop.2018.02.043

Wikberg, H., Leppävuori, J., Ohra-Aho, T., and Liitiä, T. (2017). "CatLignin - Reactive lignin for phenol replacement in resins," in: Proceedings of Nordic Wood Biorefinery Conference, Stockholm, Sweden, pp. 94-97.

Windeisen, E. and Wegener, G. (2012). "Lignin as building unit for polymers," in: Polymer Science: A Comprehensive Reference, K. Matyjaszewski, and M. Martin (eds.), Elsevier, Amsterdam, Netherlands, pp. 255-265.

Wongtanyawat, N., Lusanandana, P., Khwanjaisakun, N., Kongpanna, P., Phromprasit, J., Simasatitkul, L., Amornraksa, S., and Assabumrungrat, S. (2018). "Comparison of different kraft lignin-based vanillin production processes," Computers \& Chemical Engineering 117, 159-170. DOI: 10.1016/j.compchemeng.2018.05.020

Wu, S., and Zhan, H.-Y. (2001). "Characteristics of demethylated wheat straw soda lignin and its utilization in lignin-based phenolic formaldehyde resins," Cellulose Chemistry and Technology 35(3-4), 253-262.

Xu, C., Cheng, S., Yuan, Z., Leitch, M., and Anderson, M. (2012). "Production of biophenols and bio-based phenolic resins from lignin and lignocellulosic biomass," in: Lignin: Properties and Applications in Biotechnology and Bioenerg, R. J. Paterson 
(ed.), Nova Science Publishers, Hauppauge, NY, pp. 183-210.

Yang, W., Rallini, M., Natali, M., Kenny, J., Ma, P., Dong, W., Torre, L., and Puglia, D. (2019). "Preparation and properties of adhesives based on phenolic resin containing lignin micro and nanoparticles: Comparative study," Materials \& Design 161, 55-63. DOI: $10.1016 /$ j.matdes.2018.11.032

Yasuda, S., Hamaguchi, E., and Asano, K. (1999). "Ready chemical conversion of acid hydrolysis lignin into water-soluble lignosulfonate III: Successive treatment of acid hydrolysis lignin and a lignin model compound by phenolation and arylsulfonation," Journal of Wood Science 45(3), 245-249. DOI: 10.1007/BF01177733

Yoshikawa, T., Yagi, T., Shinohara, S., Fukunaga, T., Nakasaka, Y., Tago, T., and Masuda, T. (2013). "Production of phenols from lignin via depolymerization and catalytic cracking," Fuel Processing Technology 108, 69-75. DOI: 10.1016/j.fuproc.2012.05.003

Youe, W.-J., Lee, S.-M., Lee, S.-S., Lee, S.-H., and Kim, Y. S. (2016). “Characterization of carbon nanofiber mats produced from electrospun lignin- $g$-polyacrylonitrile copolymer," International Journal of Biological Macromolecules 82, 497-504. DOI: 10.1016/j.ijbiomac.2015.10.022

Yu, G., Li, B., Wang, H., Liu, C., and Mu, X. (2013). "Preparation of concrete superplasticizer by oxidation-sulfomethylation of sodium lignosulfonate," BioResources 8(1), 1055-1063. DOI: 10.15376/biores.8.1.1055-1063

Zhang, M., and Ogale, A. A. (2014). "Carbon fibers from dry-spinning of acetylated softwood kraft lignin,” Carbon 69, 626-629. DOI: 10.1016/j.carbon.2013.12.015

Zhang, W., Dehghani-Sanij, A. A., and Blackburn, R. S. (2007). "Carbon based conductive polymer composites," Journal of Materials Science 42(10), 3408-3418. DOI: $10.1007 / \mathrm{s} 10853-007-1688-5$

Zhou, H., Lou, H., Yang, D., Zhu, J. Y., and Qiu, X. (2013). "Lignosulfonate to enhance enzymatic saccharification of lignocelluloses: role of molecular weight and substrate lignin," Industrial \& Engineering Chemistry Research 52(25), 8464-8470. DOI: $10.1021 / \mathrm{ie} 401085 \mathrm{k}$

Zhu, W., and Theliander, H. (2015). "Precipitation of lignin from softwood black liquor: an investigation of the equilibrium and molecular properties of lignin," BioResources 10(1), 1696-1714. DOI: 10.15376.10.1.1696-1714

Zhu, W., Westman, G., and Theliander, H. (2014). "Investigation and characterization of lignin precipitation in the LignoBoost process," Journal of Wood Chemistry and Technology 34(2), 77-97. DOI: 10.1080/02773818.2013.838267

Zoumpoulakis, L., and Simitzis, J. (2001). "Ion exchange resins from phenol/ formaldehyde resin-modified lignin," Polymer International 50(3), 277-283. DOI: 10.1002/pi.621

Zuluaga, C. L., Du, J., Chang, H. M., Jameel, H., and Gonzalez, R. W. (2018). "Lignin modifications and perspectives towards applications of phenolic foams: A review," BioResources 13(4), 9158-9179. DOI: 10.15376.13.4.9158-9179

Article submitted: February 20, 2019; Peer review completed: April 12, 2019; Revised version received: June 7, 2019; Accepted: June 8, 2019; Published: June 20, 2019.

DOI: 10.15376/biores.14.3.Demuner 